\title{
Homelessness and incarceration: A reciprocal relationship?
}

\section{Introduction}

This article examines the relationship between incarceration and homelessness using a unique (Australian) longitudinal panel dataset that involves both homeless and at risk individuals, and which observes changes in housing and incarceration circumstances over time. The nexus between homelessness and criminality has a long history, dating back over six centuries. In medieval England vagrancy was described as the 'mother and root of all vices' and various laws were enacted to punish 'vagabond[s], rogues and other idle and disorderly persons' (Ribton-Turner 1972:104). At the start of the twentieth century sociologists in the US found evidence of criminal behaviour among homeless men (Anderson 1923; Sutherland and Locke 1936). And, since the 1970s both populations have grown rapidly in the US, and to a lesser extent Australia. Contemporary studies of homelessness consistently report a positive association with incarceration, while studies of criminal offenders have long reported high rates of homelessness, both as a precursor to incarceration, but also as an outcome. Finally, both homelessness and incarceration increase risks of poor physical and mental health, substance misuse, as well as protracted social and economic exclusion (Herrman et al. 1989; Baldry et al. 2006; Metraux et al. 2007; Greenberg and Rosenheck 2008; Geller and Curtis 2011; Cutcher et al. 2014; Australian Institute of Health and Welfare 2015; Australian Institute of Health and Welfare 2015).

Despite a large body of empirical evidence suggesting a strong association between incarceration and homelessness, identifying the extent to which the association may reflect causal relationships in one or both directions has been limited by the use of cross-sectional studies that rely on convenience samples of either prisoners or the homeless. Despite a 
recognition that transitions from both prison and homelessness are 'best understood in a longitudinal farmework' (Visher and Travis 2003:89; Blasi 1990), in the US, UK and Australia there have only been a small number of longitudinal studies. Further, these studies typically limit their samples to either ex-prisoners or homeless persons (Metraux and Culhane 2004; Baldry et al. 2006; Baldry et al. 2013; Fischer et al. 2008; Cutcher et al. 2014). The exception is Geller and Curtis (2011). They draw on the Fragile Families and Child WellBeing study from the US to examine the extent to which formerly incarcerated men faced greater housing insecurity after their time in prison and jail than other men. Due to the nature of the sample they could compare the effects of incarceration on housing stability with an equally disadvantaged group of men who had not previously been incarcerated. Controlling for a range of demographic and socioeconomic covariates, they found that recently incarcerated men faced significantly higher odds of homelessness and housing insecurity compared to men who had never been incarcerated. Geller and Curtis's study makes a significant contribution but they examine the relationship between incarceration and homelessness in one direction only - the increased risk of homelessness and/or housing insecurity among formerly incarcerated and non-incarcerated men. Further, their study is limited to fathers. Fathers may well have different housing, homelessness and incarceration careers than what might be observed in a sample not conditioned on parental status. Finally, although they utilise a wide set of controls their estimates could still be biased by omitted variables due to unobserved characteristics that make some individuals more prone to incarceration and more prone to homelessness (eg childhood experiences of violence).

Thus, although prior studies have advanced our understanding in a number of ways, there is still a way to go to demonstrate if a causal relationship between homelessness and incarceration exists, and if it does, its magnitude or its direction. In particular, there is a need to progress our understanding of the extent to which the relationship between homelessness 
and incarceration might be mediated by other factors, both structural and individual. The later issue is of particular importance as many of the characteristics associated with homelessness are also correlated with incarceration. Similarities include lower education levels (Baldry et al. 2006; Metraux et al. 2007; Greenberg and Rosenheck 2008; Geller and Curtis 2011), limited employment records (Geller and Curtis 2011; Australian Institute of Health and Welfare 2015), high rates of mental and physical illness (Herrman et al. 1989; Herrman et al. 1991; Hodder et al. 1998; Buhrich et al. 2003; Butler et al. 2006; Greenberg and Rosenheck 2008; Johnson and Chamberlain 2011; Baldry et al. 2013; Cutcher et al. 2014; Australian Institute of Health and Welfare 2015), and substance misuse (Johnson and Chamberlain 2008; Butler et al. 2011; Baldry 2014; McVicar et al. 2015). In addition, empirical studies indicate that individual characteristics dynamically interact with housing and labour market conditions (Curtis 2013). These interactions can constrain opportunities that further amplify the effect of individual disadvantage.

This paper contributes to the literature by directly addressing these lacunas. Our empirical analysis relies on a unique longitudinal panel dataset called Journeys Home (JH). $\mathrm{JH}$ is a broad based longitudinal panel study of both at risk and homeless individuals with frequent and accurate measures of exposure to homelessness and incarceration, as well as potentially confounding factors such as substance use, health, employment status and biographic information. First, this allows us to investigate whether exits from incarceration lead to homelessness and then whether homelessness leads to incarceration. Second, to address the possibility that the correlations observed in the descriptive data may be driven by other factors, we exploit the longitudinal feature of the data in individual fixed effects models that control for all time-invariant differences between respondents and may explain that they are both more prone to homelessness and more prone to incarceration. These models also include a wide range of time-varying controls to account for changes in respondents' 
circumstances such as employment status, health status, and substance use. Third, we exploit spell data - that is a 10-day block accommodation calendar - to examine the timing of those effects by estimating monthly impacts of incarceration and monthly impacts of homelessness between 1 and 24 months after exit, using our fixed effects models. We also investigate whether some specific types of homelessness and precarious housing matter in terms of the effects of incarceration on homelessness and vice versa.

Overall, our results confirm a strong positive relationship between incarceration and homelessness, both prior to and also during the JH study period. However, in individual fixed effects models with time-varying controls we find that homelessness does not increase the risk of incarceration and that incarceration does increase the probability an individual will become homeless, but not immediately. Specifically although the immediate effect of incarceration is modest (a 3 percentage points increase), it increases 6 months after release (to around 12 percentage points) and persists for a further 11 months for specific types of precarious housing. More precisely, we find that in the 6 to 17 months post-release, respondents most often stay in boarding houses or with friends (with no alternative) rather than becoming literally homelessness. Previous studies have noted that recently released prisoners rely heavily on family members for housing, as well as financial and emotional support (Naser and LaVigne 2006). The delayed effect we observe on precarious housing suggests that ex-prisoners' social, economic and emotional support deteriorates over time. This empirical contribution provides policy makers with new evidence that supports existing interventions designed to reduce the risk of homelessness among recently discharged prisoners, but also suggests that such interventions should be extended to mitigate the persistent effect of incarceration on precarious housing. Finally, when examined from the other direction, we found that homelessness, whether defined cross-sectionally or dynamically, narrowly or broadly, had no effect on incarceration. Methodologically, our 
results point to the importance of using rich and reliable longitudinal data to separate causal effects from associations between homelessness and incarceration that are driven by (observed) time-varying characteristics and (unobserved) time-invariant individual characteristics.

The paper is structured as follows. First, we review the literature paying particular attention to studies that examine housing instability and homelessness among prisoners and those that examine incarceration in the homeless population. We then include a detailed discussion of our definitions, data and methods. The key here is our use of longitudinal data. In the next section (5) we describe our results. Then after examining the effect of incarceration and homelessness further with a series of robustness checks, we conclude with a discussion of potential policy opportunities.

\section{Background}

Social researchers have approached the link between incarceration and homelessness from two directions. On the one hand are those who examine experiences of homelessness among currently and formerly incarcerated persons. On the other are those that have examined incarceration histories among homeless individuals. Despite two separate literatures scholars agree - homelessness can be a precursor to incarceration, as well as an outcome.

Studies from the US and UK report that homelessness is a relatively common experience prior to incarceration (Michaels et al. 1992; Ditton 1999; Hughes et al. 2001). For instance, James and Glaze (2006) found that among jail inmates without a mental health problem 9 per cent were homeless in the year prior to jail entry; among those with a mental health problem the rate was 17 per cent. Similarly, a longitudinal study of over 1,400 prisoners sentenced to between one month and four years in the UK found that 15 per cent reported being homeless prior to entering custody (Williams et al. 2012). Other studies report 
that homelessness is a relatively common outcome for people leaving jail (Visher et al. 2004; Kushei et al. 2005). In a large study of New York State prisons, Metraux and Culhane (2004) found that 11.4 per cent of the 48,424 people released from prison entered the New York shelter system in the two years following their release. Although studies find considerable variation in the proportion of incarcerated persons with an experience of homelessness (Shlay and Rossi 1992; Eberle et al. 2000), a synthesis of major studies on homelessness and incarceration in the US by Metraux and his colleagues (2007) suggest that taken together the research indicates that prior to entering prison about 1 in 10 prisoners were, or had recently been, homeless and 'at least the same percentage of those who leave prison end up homeless' (p.5).

Although limited in number, Australian studies report similar findings with between 10 and 20 per cent of prisoners indicating that prior to entering prison they were sleeping rough or staying in emergency or temporary accommodation (Baldry et al. 2006; Cutcher et al. 2014; Australian Institute of Health and Welfare 2015; Payne et al. 2015). Among those leaving prison reported rates of homelessness range from 10-25 per cent (Baldry et al. 2006; Australian Institute of Health and Welfare 2015).

Incarceration rates among homeless persons are typically much higher than in the general population. US studies suggest that anywhere between one fifth and two thirds of all homeless people have spent time in prison (Redburn and Buss 1986; Rossi 1989; Burt 1992; Shlay and Rossi 1992; Piliavin et al. 1993; Burt et al. 1999; Culhane and Metraux 2008). The extant Australian literature is limited to administrative data on service users, or small samples of sub-groups such as young people, or the long-term homeless. These studies yield very different results with three per cent among clients of specialist homelessness services reporting they had recently exited a custodial setting (Australian Institute of Health and 
Welfare 2014), to over 80 per cent in a sample of the long-term homeless reporting an incarceration spell at some point in their lives (Johnson et al. 2014).

In drawing on US studies we are mindful of the differences between the two countries, three of which are highly relevant here. First, incarceration rates in the US are much higher than Australia, or anywhere else in the world. Indeed, in 2014 the incarceration in the US rate was 612/100,000 (Carson 2015). In comparison the national imprisonment rate in Australia in 2015 was 196 persons per 100,000 adult population (Australian Bureau of Statistics 2015). Second, in the United States Public Housing Authorities (PHA) can exclude individuals with a criminal record therefore limiting the support ex-prisoners can get from their families (Curtis et al. 2013). In Australia, no such exclusionary practices exist. There is good reason to assume the higher rate of incarceration in the US might result in a stronger association between homelessness and subsequent entry into the penal system compared to Australia. With respect to the association between incarceration and subsequent homelessness, the higher flow of prisoners out of the US penal system coupled with policy constraints limiting access to public housing for ex-prisoners, suggests that the association between incarceration and subsequent homelessness might also be stronger in US than in Australia. However, without comparable data we cannot test these assumptions.

\section{Two different explanations}

Two complementary approaches are used to explain the relationship between incarceration and homelessness. The first, which we term the 'risk' thesis, largely focuses on homelessness as an outcome of incarceration. It suggests that high rates of homelessness among exprisoners occur because cultural, social and economic barriers undermine housing stability among ex-prisoners. These include discrimination, limited family support, as well as inadequate discharge planning and access to appropriate support services. Further, 
incarceration can be a major barrier to employment (Pager 2003). Limited employment opportunities and lower wages mean that many ex-prisoners often lack the economic resources necessary to secure and maintain independent housing (Massoglia et al. 2012:146). Not only do these factors increase the risk of housing instability and homelessness, but if homelessness occurs then ex-offenders face an increased likelihood of re-incarceration. Indeed, a pattern linking homelessness with high rates of re-incarceration has been reported in a number of studies in the US, Australia and elsewhere (Carlisle 1996; De Lisi 2000; Metraux and Culhane 2004; Baldry et al. 2006; Geller and Curtis 2011; Payne et al. 2015). Interestingly though, Cobb-Clark et al. (2016) find no significant relationship between previous incarceration and the duration of homeless episodes once controlling for timeinvariant heterogeneity. However, they do not study whether ex-inmates are more likely to enter homelessness.

The second approach - the 'criminogenic' hypothesis' (McCarthy and Hagan 1991) seeks to explain how homelessness can lead to incarceration. The crux of this argument is that homeless persons resort to 'crimes of desperation' in order to survive (Gowan 2002). Prior studies show that activities such as begging, drug dealing, street sex work and shoplifting, although illegal, are simply strategies designed to make ends meet (Baxter and Hopper 1981; Snow et al. 1989; Snow and Anderson 1993; Wolch and Dear 1993; Glasser and Bridgman 1999; Johnson et al. 2008). Along with these strategies are behaviours that increase the likelihood of attracting police attention. These behaviours include breaking into a place to sleep or to escape the elements, sleeping in a park or in a car, as well as disorderly conduct and public intoxication.

Studies that examine the criminal activities of homeless individuals provide some support for this argument. In their study of over 700 randomly selected homeless men in Austin, Texas Snow, Baker and Anderson (1989) found that the crimes they committed were 
neither 'terribly serious or dangerous' (p.537). They found that 80 per cent of the crimes committed by the homeless men in their sample could be classified as Part II crimes - that is minor misdemeanours and less serious felonies such as violating city ordinances, shop lifting, disorderly conduct, substance related crime and the like. Among non-homeless men, Types II crimes were less common, accounting for only 35 per cent of all the crimes committed. Other studies in the US have also found that the criminal offences committed by homeless individuals are typically trivial and non-violent (Banks and Fairhead 1976), and that compared to non-homeless men, homeless people are less likely to be perpetrators of serious crimes (Foscarinis 1996). While some studies have identified substantial rates of criminal justice involvement for major crimes among the homeless population, this sort of criminal activity generally precedes homelessness.

Although no Australian studies to our knowledge have attempted to examine the arrest records of homeless individuals, there is evidence to suggest the situation might be similar in Australia. Walsh (2011) for instance highlights a range of legislative arrangements that exist around the country which increase the likelihood of contact with the criminal justice system such as the criminalization of begging and the prohibition on drinking in public. In addition some US and Australian cities have enacted ordinances that criminalise the act of sleeping in public, although there is considerable variation between jurisdictions.

Further empirical support for the criminogenic argument comes from Fischer and colleagues' (2008) longitudinal study of 207 mentally ill homeless individuals. They found that being homeless (both on the streets and in shelter) predicted increases in non-violent crime, and sheltered homelessness and symptomatic severity predicted increases in violent crime. Young homeless people are also more likely to commit criminal offences after, rather than before leaving home. In their study of 390 homeless adolescents, McCarthy and Hagan (1991) found that after controlling for age, gender, and the number of previous homeless 
experiences, the most potent explanatory factor with respect to criminal behaviour is 'the current homeless situation'.

Despite enduring interest in the relationship between incarceration and homelessness evidence about the causal relationship remains unclear. Yet the nature of the relationship is crucial from a policy perspective for a number of reasons. It is well recognized that there are significant costs associated with the over representation of the homeless in the criminal justice system, and also the over representation of people who have been in the criminal justice system among the homeless. And, despite efforts to reduce homelessness among exprisoners and to reduce involvement with the criminal justice system among homeless persons, it is far from clear that such programs have been effective. A better understanding of the association between incarceration and homelessness can assist policy makers in the prevention of crime, as well as in reducing homelessness. However, what is required are longitudinal data that contain frequent and accurate measures of exposure to homelessness and incarceration. In the past this sort of data was unavailable but the situation has changed with the Journeys Home dataset.

\section{Study design}

\section{$\underline{4.1 \text { Longitudinal data }}$}

The primary data utilised in this analysis is a panel longitudinal study known as Journeys Home. JH is a large-scale, broad based interviewer-administered survey that followed a sample of Australian welfare payment recipients exposed to homelessness or housing insecurity between September 2011 and May 2014. Journeys Home is ideal for examining the relationship between incarceration and homelessness as it captures rich information on participants' social and demographic characteristics, their housing circumstances and their contact with the justice system over time, information on employment and voluntary work, 
service use and social networks, health and well-being, exposure to violence as well as measures of income and financial stress, as well as biographical information prior to the survey.

In addition to collecting detailed information about respondents' housing circumstances at each of the six interviews (or waves), the questionnaire included a housing calendar designed to capture all changes in housing circumstances between interviews.

Respondents were asked about all their moves into and out of particular accommodation in 10 days blocks. These data allow us to create very detailed indicators of the respondents' housing status and the timing of homelessness and incarceration spells. In addition, both the housing calendar and wave data enable us to construct homelessness spells according to different definitions of homelessness.

\section{$\underline{4.2}$ Sample design}

In Australia, Centrelink is the sole agency that administers welfare benefits. Administrative data collected by Centrelink provided the sample frame for Journeys Home. Around 5 million, or nearly one quarter of the Australian population, receive some form of support from Centrelink. While most at risk and homeless households likely receive some form of assistance from Centrelink, the risk of homelessness is very low for the vast majority of individuals captured in the administrative data (Wooden et al. 2012). In order to identify a more relevant sample JH capitalized on a set of protocols Centrelink staff had been following since 2010 to identify customers they assessed to be either 'homeless' or 'at risk of homelessness'. A third group, although not flagged by Centrelink staff as 'homeless' or 'at risk' of homelessness, was identified. This group have characteristics similar to those flagged by Centrelink as 'homeless' or 'at risk' thus constituting a group that is, at least in a statistical sense, vulnerable to homelessness. 
These protocols resulted in a total population of 139,801 individuals being identified as (i) homeless, (ii) at-risk of homelessness, or (iii) vulnerable to homelessness. From this population, a stratified random sample of 2,992 individuals across 36 locations covering all states and territories was selected for interview. A small number $(\mathrm{N}=273)$ were subsequently determined to be out of scope, primarily because they had moved out of the designated survey interview area prior to fieldwork commencing. This left a sample of 2,719 , of which almost 62 per cent $(n=1,682)$ agreed to participate in a wave 1 interview, which was conducted between September and November 2011. As of wave 1, 94 per cent of JH respondents had been homeless at some point in their lives, compared with 13 per cent in the Australian population aged 15 years and over (Australian Bureau of Statistics, 2014). With respect to incarceration, 4.7 per cent of $\mathrm{JH}$ respondents had been to prison in the 6 months preceding the survey, while the national imprisonment rate was 0.19 per cent in 2014 (Australian Bureau of Statistics, 2014). These high levels of housing insecurity and incarceration in our sample provide a unique opportunity to analyse behaviours and outcomes of very disadvantaged individuals who are rarely observed in traditional surveys. Still, our sample is representative of the Australian subpopulation experiencing homelessness and incarceration. For instance, 11 per cent of respondents experiencing an incarceration spell were literally homeless prior to being incarcerated and 35 per cent were homeless broadly defined. This is very similar to the 10 per cent and 25 per cent reported in the Australian literature (Baldry et al. 2006; Australian Institute of Health and Welfare 2015; Payne et al. 2015). In addition, 1 per cent of homeless spells are preceded by incarceration which is similar to the rates of incarceration of 3 per cent recorded among users of homelessness services in Australia (Australian Institute of Health and Welfare 2014).

Follow-up interviews were subsequently conducted at six-monthly intervals, and respondents were interviewed in person whenever possible, with telephone interviews 
conducted in situations where face-to-face interviews were not feasible. Of the original 1,682 wave 1 respondents 91 per cent (wave 2), 88 per cent (wave 3), 86 per cent (wave 4), 85 per cent (wave 5) and 83 per cent (wave 6) were re-interviewed ${ }^{1}$.

We focus on the balanced panel - that is on the 1211 respondents (or 72 per cent of the wave 1 sample) who were either interviewed in all six waves or who missed an interview because they were in prison at the time. Importantly, attrition is unlikely to be a major concern since the characteristics of respondents at wave 1 are not significantly different from those of respondents' who answered all 6 waves of the survey (Melbourne Institute 2014). However, for our purpose here we do find differences in homelessness and incarceration experiences between wave 1 respondents and the balanced panel. To deal with this issue the statistical method used in the analysis (individual fixed effects) controls for respondents' permanent characteristics, as well as a large number of time-varying characteristics. This addresses concerns related to possible non-random attrition correlated with those characteristics ${ }^{2}$

Finally, a unique feature of $\mathrm{JH}$ was that it sought permission to link respondents' data to administrative records held by Centrelink. Over 98 per cent consented. Administrative data provide accurate information on respondents' welfare history but also about incarceration spells while on welfare benefits.

\subsection{Measurement}

\subsubsection{Homelessness}

Journeys Home does not explicitly define homelessness, but rather identifies a range of housing circumstances people live in. This approach provides an opportunity to apply

\footnotetext{
${ }^{1}$ Further information on the Journeys Home population and sample design are discussed in Wooden et al. (2012).

2 This means that our results are generalisable to the wave $1 \mathrm{JH}$ sample, which is a sample of extremely disadvantaged Australians, but not to the general population.
} 
different definitions of homelessness. We categorize respondents as homeless in two different ways reflecting differences in the way US and Australian researchers define homelessness. First, we apply a broad approach. Here a respondent is categorised as homeless if she/he spent any time between survey waves (i.e. over 6 months-periods): sleeping rough; squatting in an abandoned building; in emergency or crisis accommodation; in a caravan, cabin or mobile home; in a hotel or motel; in a boarding house or hostel; or with friends with no other alternative. This approach aligns with the way homelessness is often defined in Australia (Chamberlain and Mackenzie 1992; FaHCSIA 2008).

We then break the broad definition into two sub-definitions that more closely reflect the way researchers in the US understand homelessness. First, a respondent is defined as literally homeless if they spent any time between survey waves (i.e. over 6 months-periods): sleeping rough; squatting in an abandoned building; in emergency or crisis accommodation. We then classify respondents who spent time in a caravan, cabin or mobile home; in a hotel or motel; in a boarding house or hostel; or with friends with no other alternative, as precariously housed ${ }^{3}$.

\subsubsection{Incarceration}

The main incarceration variable is constructed for each wave of the survey (i.e. 6 monthsperiods) from calendar information. It is then corrected using information from Centrelink on suspensions and/or cancellations of welfare benefits because of incarceration (since the last wave). We further correct calendar information with respondents' answers at each interview about any other incarceration spells not entered in the calendar, as well as when interviews were not held because respondents were incarcerated. Specifically, for the 1,211 respondents that make up our balanced panel, we define a dummy variable at each wave equal to 1 if the

\footnotetext{
${ }^{3}$ Note that although the US tradition is to separate literal homelessness from precarious housing, a broader definition of homelessness encompassing both is being used for service provision (Hearth Act, 2009).
} 
respondent was incarcerated since the last wave according to any of the four sources of information outlined above. The incarceration variable equals 0 if the calendar information identifies that there are no incarceration spells in that period and the three corrections are either 0 or missing. Finally, we treat the incarceration variable as missing if the calendar information is missing and the three corrections are 0 or missing. These corrections make a big difference: out of the 286 incarceration spells identified in our sample, only 131 are identified in the calendar (46 per cent). We therefore chose to use the corrected incarceration variable built at the survey wave level (referred to as 'wave data') for our main specification rather than the uncorrected variable from the accommodation calendar data (referred to as 'spells data'), which only identifies the calendar information. We test the robustness of our results to the definition of the incarceration variable in section 5.5.

\subsection{Econometric modelling: Fixed effects estimates}

The literature clearly establishes that incarceration and homelessness are associated but whether this relationship is causal remains unclear. The descriptive evidence may be flawed by the fact that the impact could run in both directions (reverse causality) and/or by differences in individual and contextual characteristics that influence both homelessness and incarceration (unobserved heterogeneity). However, by exploiting the richness of the information provided by the Journeys Home survey and its longitudinal dimension we can start to develop a better understanding of the extent to which the associations between homelessness and incarceration reflect causal relationships acting in one or both directions. Specifically, in order to deal with reverse causality, we introduce a one-period difference between homelessness and incarceration. The idea is that incarceration can only cause homelessness if the respondent is incarcerated prior to being homeless (and vice versa). Using wave data we cannot time these events if they happen in the same wave, so we lag 
incarceration by one wave to make sure that in estimating the effect of incarceration on homelessness, incarceration happened first.

To deal with unobserved heterogeneity we estimate a series of linear models for homelessness, initially with no controls other than wave dummies, then progressively introducing observable time-invariant and time-varying variables to control for observable characteristics which may lead some respondents to being more or less prone to homelessness and incarceration.

Finally, we include individual fixed effects that control for all time-invariant differences between respondents. Essentially instead of comparing across different individuals who have different characteristics that may explain why some are both more likely to be homeless and incarcerated, we compare within individuals at different points in time. By observing respondents' homelessness and incarceration statuses 6 times by 6 -month intervals, we can look at whether individuals are more likely to be homeless in waves following waves in which they were incarcerated compared to waves in which they were not incarcerated. This ensures that our estimates cannot be driven by any time-invariant unobserved heterogeneity. Our final (and preferred) model includes individual fixed effects and all time-varying observable controls:

$$
H_{i t+1}=\alpha_{1}+\alpha_{2} I_{i t}+\alpha_{3} X_{i t}+\gamma_{i}+\tau_{t+1}+\eta_{i t+1}
$$

where $H_{i t+l}$ denotes homelessness (whether literal or precarious housing) of individual $i$ at time $t+1 ; I_{i t}$ denotes incarceration of individual $i$ at time $t ; X_{i t}$ represents time-varying observable controls; $\gamma_{i}$ and $\tau_{t+l}$ are individual and time fixed effects respectively and $\eta_{i t+l}$ is the error term. Time-invariant controls include: a dummy for having ever been incarcerated before Journeys Home, a dummy for having ever been homeless before Journeys Home, a dummy for male, a dummy for being indigenous, a dummy for being born in an Englishspeaking country, a dummy for not living with biological parents at 14 , five dummies for the 
female and male caregivers (substance abuse, long-term unemployment, mental health, incarceration, gambling), the Big 5 personality traits (extroversion, agreeableness, conscientiousness, emotional stability, openness to experience), cognitive ability (0-7 score), missing data indicators. Two sets of time-varying controls are used. The first set includes: respondent's age and age square, a dummy for being divorced/separated, two dummies for the level of education (high-school graduate, some college), dummy for being employed, four dummies for the use of substances (smoking daily, risky drinking ${ }^{4}$, cannabis, illegal street drugs), a dummy for reporting good health, seven dummies for the State of residence. The second set of time-varying controls include: a dummy for having resident children under 18, two dummies for having experienced violence in the last 6 months (physical and sexual), the proportion of time employed in the last 6 months, total outstanding debt, a dummy for having contacts with family less than once a month, a dummy for all/most friends being homeless, a dummy for all/most friends using illicit drugs and missing data indicators.

In estimating (1) we are investigating whether incarceration over the survey period tends to precede homelessness, controlling for all time-invariant differences between individuals, whether observed or unobserved, and for observable time-varying differences. Conditional on these controls, we interpret a statistically significant relationship from incarceration to subsequent homelessness as indicating a potentially causal relationship from incarceration to homelessness. Ultimately of course time-varying factors may still bias our results. For instance, we cannot rule out that an unobserved event happening prior to homelessness and incarceration leads to both homelessness and incarceration.

In the same way we explore the potential impact of homelessness on incarceration, estimating linear models first including only wave dummies as controls, then including

\footnotetext{
4 This variable is defined following the Australian National Health and Medical Research Council definition, as 21 or more standard drinks per week on average (i.e. more than 2 standard drinks per day).
} 
observable time-varying and time-invariant controls, and finally replacing the time-invariant observed controls with individual fixed effects. Our final model is given by (2):

$I_{i t+1}=\alpha_{1}+\alpha_{2} H_{i t}+\alpha_{3} X_{i t}+\gamma_{i}+\tau_{t+1}+\eta_{i t+1}$

where $I_{i t+l}$ denotes incarceration of individual $i$ at time $t+1 ; H_{i t}$ denotes homelessness

(whether literal or precarious housing) of individual $i$ at time $t$; $X_{i t}$ represents time-varying

observable controls; $\gamma_{i}$ and $\tau_{t+l}$ are individual and time fixed effects respectively and $\eta_{i t+l}$ is the error term.

\section{Results}

\section{$\underline{5.1 \text { Descriptive results }}$}

In Table 1 we compare the prevalence of homelessness and incarceration for the full sample and the balanced panel to determine if respondents who remained in the survey for six waves are different from those who dropped out. We also include results from the six waves of the balanced panel to provide an indication of how the sample evolved over time. Finally, we include spell data to describe the participants' accommodation spells over the course of the study.

Respondents in the full sample were slightly more likely to have experienced some form of homelessness, both broadly and literally defined, in the six months prior to $\mathrm{JH}$, compared to the balanced panel at wave 1 . With respect to incarceration just under 1 in 20 people (4.7 per cent) in the full sample had been incarcerated in the six months preceding JH. In the balanced panel the rate falls to 3.8 per cent. Both results suggest some differences between the full sample and the balanced panel. Indeed, comparing the two samples across 61 different variables shows there are 15 significant differences between the two, and that those who remained in the survey were less disadvantaged than those who dropped out (Table A1 
appendix). Importantly, in our preferred specification that follows we control for all of those characteristics and all time-invariant characteristics.

Comparing the characteristics of the balanced sample over six waves shows that across all measures of homelessness the rate declines - broadly defined it declined from 45 per cent at wave 1 to to 31 per cent over the six waves, and by about half when we use a literal definition (from 17.4 per cent to 9.4 per cent). We also observe marked declines in the proportion of respondents who had ever stayed in boarding houses, with friends or in a caravan park or hotel. A decline in the prevalence of homelessness is to be expected given that the homeless population was over-sampled in wave 1 and that homelessness is a transitory state for many respondents (Kuhn and Culhane 1998). Of interest, the rate of incarceration remains much the same, at around 4 per cent.

In the last column we use spell data from the accommodation calendar to examine the participants' accommodation spells over the course of the study. We found that 36 per cent of the spells are homeless spells (broadly defined) - 9 per cent of which are literal homelessness spells and 27 per cent are spells in various forms of precarious housing. Incarceration spells accounted for 0.9 per cent. Compared with the lower homeless and higher incarceration rates in column 3, this suggests that homeless spells tend to be shorter than six months, while incarcerations spells tend to be longer. Further, people with multiple accommodation housing spells are over-represented in the spell data. These respondents tend to be younger, more involved with drugs and experiencing more violence (Table A1). In order to take these differences into account in the regression analysis that use these data, we use our preferred individual fixed effects model with clustered standard errors at the individual level.

Table 1 about here

Table 2 provides clear evidence of a positive association between incarceration and homelessness, with just over 1 in 10 of those who had never been homeless prior to JH 
reporting they had been incarcerated at some point in their lives. Among those who had ever been in precarious housing just under 16 per cent had been incarcerated. In contrast, 41 per cent of the individuals who had been literally homeless prior to JH reported they had been incarcerated.

\section{Table 2 about here}

Earlier in the paper we emphasised the importance of analysing the relationship between homelessness and incarceration from a dynamic perspective. Thus, while the results presented above confirm a strong positive association between incarceration and homelessness, they add little to our understanding of the nature of that association - it is impossible to identify the extent to which the association between incarceration and homelessness may reflect causal relationships acting in one or both directions (reverse causality), or the effect of differences in characteristics that lead people to become both homeless and incarcerated. By exploiting the richness of the information provided by the Journeys Home survey, its longitudinal dimension, and estimating a series of econometric models, we start to address these limitations.

\subsection{Regression results: Which has the greatest effect - homelessness or incarceration?}

Table 3 shows the results of regressions of homelessness, broadly defined, on incarceration with different econometric specifications in panels (a to e) and different sets of controls in columns. The first set of controls, both time-invariant and time-varying, are comparable to the controls used by Geller and Curtis (2011). The time-varying controls are taken at wave 1 in panels $\mathrm{b}$ and $\mathrm{c}$, and taken at time $\mathrm{t}$ in panels $\mathrm{d}$ and $\mathrm{e}$. While this set of controls enables us to compare findings, they do not take full advantage of the richness of the Journeys Home data. Consequently we include a second (or extended) set of time-varying controls, taken at wave 1 
in panels $b$ and $c$, and taken at time $t$ in panels $d$ and e. ${ }^{5}$ Results showing estimates for the control variables are given in table A2.

In the first panel (a) we present Geller and Curtis' main result. Following a similar analytic strategy to Curtis and Geller we examine the effects of being incarcerated in any of the first five waves on the likelihood of being homeless in wave 6 (panel b). Our results confirm a significant positive effect of incarceration on homelessness, but the magnitude of the effect is smaller. We found that the odds of being homeless at wave 6 are 1.8 times higher among those incarcerated in waves 1 to 5 than for those who were not. When the sample was restricted to men as per Geller and Curtis, the first set of control still yields a ratio of $1.8^{* *}$ compared to their estimate of $2.68^{* * 6}$. The difference likely reflects the fact we are looking at two countries with very different approaches to incarceration, different outcomes (homelessness vs housing instability) and that they are estimating their effect over 5 years against only 2.5 for us, among other things.

In the third panel (c) we follow the same approach (eg incarcerated in the first five waves and homeless in wave 6) but now apply a different specification (OLS) to convert the above odds ratio into marginal effects similar to those that we will estimate in the fixed effects framework. For example, when we apply no controls individuals incarcerated in any of the first five waves are 12 percentage points more likely to be homeless in the final wave; when we apply the first and second set of controls the results diminish slightly to 10.8 and 11.3 percentage points respectively. Overall, adding control variables with no timedimension, i.e. without accounting for changes in respondents' circumstances, does not alter the estimates.

\section{Table 3 about here}

\footnotetext{
${ }^{5}$ The full list of controls is given at the bottom of Table 3 .

${ }^{6}$ The coefficient reported from Geller and Curtis (2011) in panel a comes from their Table 4, column 3.
} 
Although our results support those reported by Geller and Curtis, this approach does not take full advantage of the JH longitudinal data. Consequently we modify our approach in the final two panels ( $\mathrm{d}$ and e) of Table 3 and use the data in a slightly different format. Rather than using one observation per respondent, we now exploit the six observations per respondent. This allows us to start using the timing of events by looking at the effect of incarceration in $t$ on homelessness in $t+1$. Also we can now control better by using the value of controls in $t$. In doing so we take into account how the controls evolve between waves rather than just their value at wave 1 . For example, if incarceration at wave 3 leads to family breakdown at wave 3 and then homelessness at wave 4, this specification controls for it while in panel $\mathrm{c}$ we only control for marital status at wave 1 . This approach reduces the impact of incarceration on homelessness. For example, using the extended set of controls we find that individuals have a 4 percentage point higher probability of being homeless after a wave in which they were incarcerated compared to a wave in which they were not (panel d). This effect is now insignificant. It is worth noting however that the decrease in the effect of incarceration on homelessness is not due to the modification of the incarceration variable (from "in the first 5 waves" to "in wave $t$ ") and hence the timing of the link between homelessness and incarceration. Indeed, going from panel (c) to (d) with no controls (first column) has no effect on the results $\left(0.118^{* *}\right.$ to $\left.0.120^{* *}\right){ }^{7}$

In the final panel (e) we go one step further and use individual fixed effects to control for time-invariant unobserved heterogeneity, i.e. characteristics which do not vary in time and co-determine incarceration and homelessness. This yields an insignificant estimate of 5 percentage points when we use the extended set of controls. Our initial results suggest that incarceration increases the likelihood an individual will subsequently become homeless, but

\footnotetext{
7 This is confirmed when re-estimating models $\mathrm{d}$ and e adding incarceration in $t-1$ as an explanatory variable. Basically, in model (d) with no controls, we find a significant effect of incarceration in $t$ (close to $0.100^{* *}$ ) but the effect is insignificant in $t-1$. Both coefficients are insignificant in models (d) with controls and in the three models (e) with and without controls. Results available upon request.
} 
after controlling for other events and accounting for time-invariant heterogeneity the effect is much smaller than reported by Geller and Curtis, and insignificant. The decrease in the magnitude of the effect of incarceration and loss of significance appears to be due to controlling better for confounding factors driving the relationship between homelessness and incarceration (rather than a change in the timing of the incarceration variable as explained above). In fact, insignificance is first found in model (d) when adding time-varying controls (column 2) or when going from (d) to (e), i.e. when controlling for time-invariant characteristics. $^{8}$

However, two important questions remain. First, the existing literature suggests that persons with certain characteristics (e.g mental health and/or substance misuse problems; people with ABI's, race, gender, age) are more likely to become homeless after an incarceration spell. Using wave data with our extended set of controls we do not find any conclusive evidence that different subgroups are more vulnerable to homelessness after incarceration than their counterparts. ${ }^{9}$ But importantly, risky drinking and health status appear to be jointly contributing to homelessness and incarceration (see Table A2, column 1). Despite the popular appeal of the 'risk' thesis, we found only limited evidence to support it. Incarceration does not significantly increase the risk or probability an individual will become homeless, at least not immediately. Given the strong association reported earlier, this could be because the relationship works the other way around. We investigate this question next.

As we noted earlier, a limitation with Geller and Curtis' study is that they examine the relationship between incarceration and housing instability from only one direction. Consequently, when we turn our attention to the effect of homelessness on incarceration (Table 4), we estimate only the last two models (eg panels d and e in Table 3). Applying no

\footnotetext{
${ }^{8}$ One may worry that the insignificance of our results is due to over-controlling by taking controls at time $t$, i.e. controlling for mechanisms that lead inmates to homelessness (e.g substance abuse upon release in $t$ ). Given that individual fixed effects with no controls (model (e) column 1) yield very similar insignificant estimates, it cannot be due to the timing of the controls.

${ }^{9}$ Results available on request.
} 
controls to our simple OLS model (panel a) shows that respondents who are homeless at $\mathrm{t}$ have a 1.4 percentage point higher probability of being incarcerated at the following wave than respondents who are not, and the result is significant at the $95 \%$ level. However, when we add controls, both the standard and extended sets, the effect is washed away. The fixed effect estimate (panel b) confirms this result, irrespective of which set of controls are used respondents are no more likely to be incarcerated in waves following a wave with a homeless spell than in waves where there are no homeless spells.

Our findings challenge the relationship between homelessness and incarceration suggested by the criminogenic model. Previous studies that have provided empirical support for the criminogenic model sample specific subgroups, many of whom are already homeless. Ours is a broad sample of both homeless and at risk individuals who are extremely disadvantaged. It may well be that a broader definition of homelessness dilutes the effect if certain homeless subgroups are less likely to be incarcerated. In the following section we examine the effect of different definitions of homelessness.

\section{Table 4 about here}

\subsection{Does the type of homelessness matter?}

In Australia policy makers and researchers use a broad definition of homelessness, as we do here. This has implications in terms of the size and characteristics, as well as the dynamics of the homelessness population. Earlier (section 4.1) we disaggregated our broad definition of homelessness into literal homelessness and precarious housing which included staying with friends, in a boarding house or a caravan or hotel. Using the fixed effects model with all controls we now examine whether different forms of homelessness and precarious housing matter in terms of the effects of incarceration on homelessness (Table 5) and vice versa (Table 6).

Table 5 about here 
Table 5 looks at the effects of incarceration, as well as the effects of different types of contact with the criminal justice system. Starting with our broad definition of homelessness Table 5 shows that events most likely to precede incarceration such as being stopped by the police, being held overnight by the police, or going to court, are positively and significantly related to homelessness.

When we change our definition to literal homelessness and different types of precarious housing we find that incarceration most often leads to staying with friends at the next wave than other types of accommodation ( $7.3 \mathrm{pp})$, although the result is insignificant. We also find that being stopped, held overnight, going to court or being apprehended increase the probability of staying with friends with no alternative, and the results are significant. Finally, being stopped by the police also increases the risk of being literally homeless or staying in a caravan park at the next wave.

Contacts that do not necessarily precede incarceration (eg non-custodial sentence or community based order; visits to/from Justice Officers; stopped in a vehicle by police) do not lead to an increased probability of homelessness (broadly defined), literal homelessness or spending time in precarious accommodation arrangements at the next wave. This is interesting because the relationship between those types of contacts and the type of homelessness/precarious housing may still be flawed by omitted variable bias if those contacts are for instance related to substance use. Although not a complete proof, this suggests that we are doing a good job at eliminating potential sources of biases.

Looking at the issue from the other direction, we now examine whether different forms of homelessness and precarious housing are linked to an increased likelihood of subsequent incarceration using the same fixed effects model with the extended set of controls specified earlier (model e, Table 3). Based on previous research we expected, somewhat tentatively, that if any form of homelessness was linked to a higher probability of 
incarceration it would be literal homelessness, due to the fact it is more visible and the strategies required to survive of the streets are likely to attract police attention. However, Table 6 shows that this is not the case. Indeed, none of the components of homelessness seem to matter at all - the coefficients are all small and insignificant (column 1).

Table 6 also includes others forms of contact with the criminal justice system that might occur as a result of homelessness or living in precarious housing arrangement. There is not much of an increase in any type of contact with the justice system across our five housing measures, although there are exceptions. Staying in a boarding house increases the likelihood of being apprehended by the police ( $6.7 \mathrm{pp})$, while staying in a caravan park increases the likelihood of visiting or being visited by Justice Officers (3.6pp). In contrast, staying at a friend's house decreases this likelihood. Surprisingly, we find that being literally homeless does not increase the probability of contact with the criminal justice system.

\section{Table 6 about here}

\section{$\underline{5.4 \text { From waves to spells }}$}

One of the key advantages of using wave data was that we had more accurate incarceration information (using the administrative data, respondents' corrections and respondents' status at interview). However, we had to lag the data and this means that we may have missed incarceration and homeless spells that occurred in the same wave, as well as accommodations spells that might occur between incarceration and homeless spells. While using spells data from the accommodation calendar means we cannot use the corrections, they provide a more precise picture of the sequences of accommodations spells. Spells data also allow us to investigate the timing of the effects. In the following section we use spells data to estimate 
the impact of an exit from incarceration and an exit from homelessness between 1 and 24 months later, using fixed effects models with extended controls (as per Table 3$)^{10}$.

Using spells data we found that when respondents leave prison, they enter (broad) homelessness more often than when they leave any other type of accommodation, but the effect is not immediate. Figure 1 shows that a month after exiting prison respondents do not have a higher probability of being homeless than when they exit another type of accommodation (the coefficient is 3 percentage points and insignificant). The probability of being homeless increases to 12 percentage points at the six month mark and 14 percentage points 12 months after the end of the incarceration spell. We then observe a progressive decline and the effect becomes insignificant at around 18 months.

\section{Figure 1 about here}

By differentiating by accommodation types (Figure 2) we find that the higher probability of homelessness observed during the 6-18 months post release period is driven primarily from ex-prisoners living in boarding houses, and to a slightly lesser extent with friends when they have no other alternative. This raises the question of what happens immediately after release from prison. We found that ex-prisoners were most often staying with their parents or relatives in the 5 months following release - indeed compared to any other type of accommodation the probability of staying with parents or relatives is 15 percentage points higher (See Figure A1).

Taken together the spell data suggest families play a crucial role in the immediate post release stage, but that former prisoners wear out their welcome. With few housing options available to them, and limited social, cultural, and economic resources to draw on, they often end up in precarious accommodation arrangements. These results clearly have important policy implications that we pursue further on in the paper.

\footnotetext{
${ }^{10}$ In this framework we use the controls as of the wave in which the accommodation spell under consideration occurred as we don't have the value of controls for each accommodation spell.
} 
Figure 2 about here

In addition, we analyse whether the duration of the incarceration spell has an effect on the probability to become homeless upon release. In practice we estimate the effect of incarceration on homelessness for spells that are below the median of incarceration spells: 126.5 days, i.e. about four months (Figure A2). We find that longer spells in prison have larger effects on homelessness than shorter prison spells, although both those type of prison spells have the delayed effect noted above. Recent studies suggest the length of an incarceration spells has no effect on post release outcomes such as employment (Cho and LaLonde 2005; Kling 2006). It is not entirely clear why our results run counter to these findings, although it may be that longer spells lead to greater attenuation of social support networks which are crucial in preventing homelessness. However, it is important to be cautious here. Despite a broad range of controls, the effect we observe may have more to do other factors, such as the nature of the crimes committed, which we cannot control for, rather than the effects of lengthier perison spells.

When we examine the effect of homelessness on incarceration using spell data, the results show that the effects of homelessness on incarceration is much briefer than the effect of incarceration on homelessness. Figure 3 shows that homelessness spells are 1 percentage point more likely to be followed by incarceration than any other type of accommodation in the month following the exit from homelessness, but the effect disappears immediately. Taken together, Figures 1 and 3 support our earlier findings based on wave data, about the direction of the relationship between homelessness and incarceration. In this case the length of time spent homeless does not affect the probability to be incarcerated.

Figure 3 about here

\section{$\underline{5.5 \text { Robustness checks }}$}


Although the empirical material presented so far presents a consistent picture, we ran five robustness checks of the definition of key variables and the sample, with respect to the effect of incarceration on homelessness (Table 7, column 1) and the effect of homelessness on incarceration (Table 7, column 2). Across all five checks the effect of homelessness on incarceration was similar to earlier results - the coefficients are very small and insignificant. Thus we focus on the effect of incarceration on homelessness (column 1). The first test determined whether the results differed using the uncorrected incarceration variable from the accommodation calendar. Using the uncorrected calendar variable we find a larger and significant effect $(9.4 * \mathrm{pp})$. This suggests that incarceration episodes reported in the calendar are more often related to homelessness than those which are not reported (and corrected for using administrative data, respondents' status at interview and respondents' corrections when asked if they did not report any incarceration spells in the calendar). This shows the importance of having reliable administrative data on incarceration to correct for respondents' statements.

Second, instead of controlling for variables in wave $t$ to control for time-varying factors that may affect the impact of incarceration on homelessness (and vice versa), here we control in wave $\mathrm{t}+1$. In doing so we are primarily concerned with whether we might be undercontrolling at $t$. When we control at $t+1$ the point estimate of 5.6 is similar, suggesting we are not under- or over-controlling.

\section{Table 7 about here}

Next we investigate whether controlling in wave $\mathrm{t}+1$ for incarceration and homelessness rather than in $\mathrm{t}$ affects our results. Here we are trying to make sure we are not underestimating the effects between homelessness and incarceration by focusing on spells that are too far apart when using a lagged variable. The point estimate (5.0) is identical and again insignificant. Both results show that adjusting the timing of our controls has no effect 
on our conclusions about the direction of the relationship between homelessness and incarceration.

We explore two others potential sources of sensitivity, both to the sample and to the standard errors. With respect to the standard errors rather than clustering at the individual level we cluster at a geographic level (eg where the respondents resided in wave 1). This approach assumes that any potential correlation of error terms occurs at a geographic rather than an individual level. This change does not impact on our earlier conclusions. Finally, we indicated earlier in the paper that attrition might be non-random. To explore the possible impact of non-random attrition we re-estimate our preferred models to check that selection from the JH survey in our sample is not driving our results. To run the individual fixed effects regression with lags respondents must have completed two consecutive surveys, but not all six. Our results indicate that attrition has no effect. Indeed, our estimate with the unbalanced panel (5.3pp) confirms earlier conclusions.

\subsection{Limitations}

While our study advances our understanding of the relationship between incarceration and homelessness it suffers from some limitations. For instance the use of two different types of data (waves and spell data) yielded slightly different results. The difference likely comes from the fact we corrected respondents answers with administrative data in the wave data. Indeed, relying only on the information provided by respondents tends to overestimate the effect of incarceration on homelessness, possibly because respondents report incarceration spells with larger consequences. Future research would therefore gain much from being able to exploit accurate administrative information on incarceration providing exact dates of incarceration spells. 
In addition, although controlling for the evolution of time-varying observable characteristics and time-invariant unobservables (individual fixed effects) is an important contribution, time-varying factors may still bias our results. If, for example, a health shock or other unobservable events in $\mathrm{t}$ leads independently to incarceration in $\mathrm{t}$ and homelessness in $\mathrm{t}+1$, then we may still be overstating the causal effect of incarceration on homelessness.

\section{Conclusion}

In this study we exploited a large scale national longitudinal study of individuals vulnerable to homelessness and housing instability. Our contribution is twofold. First, although incarceration is associated with future homelessness, we find that as we control for more potentially confounding factors in a fixed effects model the effect of incarceration weakens and becomes insignificant. In addition, we find little evidence that homelessness increases the likelihood of incarceration. Second, our analysis suggests that for ex-prisoners the risk of homelessness is not immediate but emerges 6 months after re-entry and persists for a further 11 months. Other studies have noted a similar pattern. For instance Cutcher and her colleagues (2014) longitudinal study of 1324 adult prisoners found that the likelihood of unstable housing following release increased at each observation - one month follow-up 6.9 per cent; 3 month follow-up 12.5 per cent; and 6 month follow up 20.3 per cent. Although Cutcher et als., study was limited to ex-prisoners and focused only on post release housing, the issue of persistence suggests the relationship between incarceration and homelessness can be broadly understood in terms of compounding social and economic disadvantage.

Much policy attention has been directed towards discharge planning and assisting individuals to re-enter the community. Indeed, ever since the reforming work of Elizabeth Fry in the eighteenth century in England, there have been many recommendations calling for properly designed and resourced post-release programs to break the link between 
incarceration and homelessness. This makes intuitive sense. Assisting ex-prisoners transition from prison through the provision of support to find housing, access services and develop new social connections is now a common feature of many carceral systems around the world. While studies find that economic hardship and stress are common experiences for recently released prisoners (Western et al. 2015), our results indicate that prisoners' vulnerability to homelessness emerges nearly half a year after release. However, a delayed and extended risk period is not unique to ex-prisoners. Studies that examine transitions out of other institutional settings such as out-of-home care (Johnson and Chamberlain 2008) and the military also provide evidence that the risk of homelessness persists over a longer time frame, often years (Metraux et al 2017). This raises questions as to whether programs that focus on mitigating the risk of homelessness in the weeks following discharge are appropriately configured. While there is tremendous variation in the focus of post-release programmes, a common feature is that they generally operate for relatively short period of time, around 3-6 months. Although we can only speculate, the fact that the likelihood of homelessness increases around the same time post-release programs typically end suggests a need to better understand the extent to which any positive outcomes generated by post-release program are sustainable or not. Finally, the longer the amount of time that elapses between discharge and homelessness the more difficult it is to determine a causal association, making the availability of (longterm) longitudinal data necessary to analyse such questions appropriately.

Nonetheless, what our results do show is that prisoners often rely on their families and relatives for accommodation in lieu of their own permanent stable housing, particularly in the immediate period following release. Whether families of ex-prisoners lack social and /or economic resources, or because of strained family relationships, we find that families are only a temporary housing solution. Staying with families may slow a downward housing trajectory but it does not stall it. As other studies have noted, ex-prisoners often enjoy a 
'honeymoon' period following their release. Because we have a longer timeframe than many studies interested in post-release outcomes we find that the honeymoon period is relatively short and family relationships deteriorates over time, an issue likely amplified by the disadvantaged nature of the sample. Families provide important social support for exprisoners and policy initiatives should examine ways to reduce the stress and pressures that incarceration and post release can put on them (Schwartz-Soicher, Geller and Garfinkel 2011).

When ex-prisoners leave the family home it often precipitates homelessness. With little social or economic capital ex-prisoner's start staying with friends temporarily or move into boarding houses because they have no other housing options available to them. Other studies have found that ex-prisoners dislike boarding houses (Baldry et al. 2002). In boarding houses there is widespread acceptance of substance use, and the criminal activity that goes to sustain it. Boarding houses are often violent places where fear and intimidation structure social interactions between residents. (Johnson et al. 2008). In boarding houses ex-prisoners find themselves living with other ex-prisoners, as well as other extremely vulnerable people including persons with serious mental health problems and this has serious implications in terms of the "quantity and/or quality of the resources and ex-offender can mobilise through his or her networks'(Walker et al. 2014:318). In boarding houses not only are ex-prisoners vulnerable to a host of adverse outcomes including re-offending and re-incarceration, but work opportunities', as well as opportunities to develop more socially and economically productive social relationships are undermined. Under these adverse conditions economic and social recovery is unlikely.

The use of boarding houses by ex-prisoners also raises concerns about the possibility of high levels of churning between the criminal justice system and the homeless service system and potential cost shifting. Indeed, both here and in the US homelessness services can 
act as a default re-entry system (see Baldry et al. 2002; 2006; Metraux et al. 2007). Assisting ex-prisoners to avoid homelessness generally and boarding houses more specifically has potentially significant policy implications, not only in term of potential cost saving to the public purse, but also in terms of improving social outcomes for this highly disadvantaged population. While current policies go part of the way to addressing the problems faced by exprisoners, the challenge facing policy makers is to develop policies that explicitly engage and support ex-prisoners families, fund extended settlement support programs, and provide a continuum of supported housing arrangements that more fully mitigate the risk of homelessness and housing instability among ex-prisoners. 


\section{References}

Anderson, N. 1923. The Hobo: The Sociology of Homeless Men. Chicago, The University of Chicago Press.

Australian Bureau of Statistics. 2015. Prisoners in Australia, 2015. Canberra, Australian Bureau of Statistics.

Australian Institute of Health and Welfare. 2014. Specialist Homelessness Services:20132014 Australia. Canberra, AIHW.

Australian Institute of Health and Welfare. 2015. The health of Australia's prisoners. Canberra, AIHW.

Baldry, E. 2014. 'Complex needs and the Justice system', in. Homelessness in Australia: An Introduction. C. Chamberlain, G. Johnson and C. Robinson (editor). Sydney, UNSW Press.

Baldry, E., D. Mcdonnell, P. Maplestone and M. Peeters. 2002. Ex-prisoners and accommodation: what bearing do different forms of housing have on the social reintergration of ex-prisoners. Melbourne, Australian Housing and Urban Research Institute.

Baldry, E., D. Mcdonnell, P. Maplestone and P. Manu. 2006. 'Ex-Prisoners, Homeleness and the State in Australia.' The Australian and New Zealand Journal of Criminology 39(1):20-33

Baldry, E., M. Clarence, L. Dowse and J. Trollor (2013). 'Reducing vulnerability to harm in adults with cognitive disabilities in the Australian criminal justice system' Journal of Policy and Practice in Intellectual Disabilities. 10(3): 222-22

Banks, C. and S. Fairhead. 1976. The petty short-term prisoner. London, The Howard League for Penal Reform. 
Baxter, E. and K. Hopper. 1981. Private Lives/Public Spaces: Homeless adults on the streets of New York. New York, Community Service Society.

Blasi, G. 1990. 'Social policy and social science research on homelessness.' Journal of Social Issues 46(4): 207-219.

Buhrich, N., T. Hodder and M. Teesson. 2003. 'Schizophrenia among homeless people in inner Sydney: current prevalence and historical trends.' Journal of Mental Health 12(1): $51-57$.

Burt, M.R. 1992. Over the Edge: The Growth of Homelessness in the 1980s. New York, Russell Sage Foundation.

Burt, M. R., L. Y. Aron, T. Douglas, J. Valente, E. Lee and B. Iwen. 1999. Homelessness: Programs and the people they serve.

Butler, T., G. Andrew, S. Allnutt, C. Sakashita, N. Smith and J. Basson. 2006. 'Mental disorders in Australian prisoners: A comparison with a community sample.' Australian and New Zealand Journal of Psychiatry 40: 272-276.

Butler, T., D. Indig, S. Allnutt and H. Mamoon. 2011. 'Co-occurring mental illness and substance use disorder among Australian prisoners.' Drug and Alcohol Review 30: 188194.

Carlisle, J. 1996. The housing needs of ex-prisoners. York, England, Joseph Rowntree Foundation.

Carson, A. 2015. Prisoners in 2014, US Department of Justice.

Caton, C., B. Dominguez, B. Schanzer, D. Hasin, P. Shrout, A. Felix, H. Mcquistion, L. Opler and E. Hsu. 2005. 'Risk factors for long-term homelessness: Findings from a longitudinal study of first-time homeless single adults.' American Journal of Public Health 95(10): 1753-1759. 
Chamberlain, C. and D. Mackenzie. 1992. 'Understanding contemporary homelessness: Issues of definition and meaning.' Australian Journal of Social Issues 27(4): 274-297.

Cho, R. and R. LaLonde. 2005. 'The Impact of Incarceration in State Prison on the Employment Prospects of Women.' Institute for the Study of Labor Discussion paper series IZA DP No. 1792.

Cobb-Clark D., N. Herault, R. Scutella and Y. Tseng. 2016. 'A journey home: What drives how long people are homeless?' Journal of Urban Economics 91 (1): 57-72.

Culhane, D. and S. Metraux. 2008. 'Rearranging the deck chairs or reallocating the lifeboats.' Journal of the American Planning Association 74(1): 111-121.

Curtis, M., H. Corman, K. Noonan and N. Reichman. 2013. 'Life shocks and homelessness.' Demography 50(6): 1-29.

Curtis, M., S. Garlington and L. Schottenfeld. 2013. 'Alcohol, drug, and criminal history restrictions in Public Housing.' Cityscape: A Journal of Policy and Research 15(3): 3752.

Cutcher, Z., L. Degenhardt, R. Alati and S. Kinner. 2014. 'Poor health and social outcomes for ex-prisoners with a history of mental disorders: A longitudinal study.' Australian and New Zealand Journal of Public Health 38(5): 424-429.

De Lisi, M. 2000. 'Who is more dangerous? Comparing the criminality of homeless and domiciled jail inmates: a research note.' International Journal of Offender Therapy and Comprative Criminology 44(1): 59-69.

Ditton, P. 1999. Mental health and treatment of inmates and probationers. Washington, DC, Department of Justice.

Early, D. W. 2004. 'The determinants of homelessness and the targeting of housing assistance. ' Journal of Urban Economics 55(1): 195-214. 
Eberle, M., D. Kraus, S. Pomeroy and D. Hulchanski. 2000. Homelessness - Causes and Effects. A Review of the Literature, Vol 1. Vancouver, British Columbia Ministry of Social Development and Economic Security.

FaHCSIA. 2008. The Road Home: A National approach to reducing homelessness. Canberra, Department of Families, Housing, Community Services and Indigenous Affairs.

Fischer, S., M. Shinn, P. Shrout and S. Tsemberis. 2008. 'Homelessness, Mental Illness, and Criminal Activity: Examining patterns over time.' American Journal of Community Psychology 42: 251-265.

Foscarinis, M. 1996. 'Downward Spiral: Homelessness and its criminalization.' Yale Law and Policy review 41(1): 1-63.

Geller, A. and M. Curtis. 2011. 'A sort of homecoming: Incarceration and houisng insecurity of urban men.' Social Science Research 40: 1196-1213.

Glasser, I. and R. Bridgman. 1999. Braving the Street: The Anthropology of Homelessness. New York, Berghahn Books.

Gowan, T. 2002. 'The nexus: Homelessness and incarceration in two American cities.' Ethnography 3(4): 500-534.

Greenberg, G. and R. Rosenheck. 2008. 'Jail incarceration, homelessness, and mental health: A National Study.' Psychiatric Services 59(2): 170-177.

Herrman, H., P. Mcgorry, P. Bennett, R. Van Reil and B. Singh. 1989. 'Prevalence of severe mental disorders in disaffiliated and homeless people in Inner Melbourne.' The American Journal of Psychiatry 146(9): 1179-1184.

Herrman, H., P. Mcgorry, J. Mills and B. Singh. 1991. 'Hidden severe psychiatric morbidity in sentenced prisoners: An Australian Study.' The American Journal of Psychiatry 148(2): $236-239$. 
Hodder, T., M. Teesson and N. Buhrich. 1998. Down and Out In Sydney: Prevalence of mental disorders, disability and health service use among homeless people in inner Sydney. Sydney, Sydney City Mission.

Hughes, T., D. Wilson and A. Beck. 2001. Trends in state parole, 1990-2000. Washington, DC, Department of Justice.

James, D. and L. Glaze. 2006. Mental health problems of prison and jail inmates. Washington, DC., Bureau of Justice Statistics.

Johnson, G. and C. Chamberlain (2008). 'From Youth to Adult Homelessness' Australian Journal of Social Issues. 43(4): 563-58

Johnson, G. and C. Chamberlain. 2008. 'Homelessness and substance abuse: Which comes first?' Australian Social Work 61(4): 342-356.

Johnson, G. and C. Chamberlain. 2011. 'Are the homeless mentally ill?' Australian Journal of Social Issues 46(1): 29-48.

Johnson, G., H. Gronda and S. Coutts. 2008. On the Outside: Pathways in and out of homelessness. Melbourne, Australian Scholarly Press.

Johnson, G., D. Kuehnle, S. Parkinson, S. Sesa and Y. Tseng. 2014. Resolving Long-Term Homelessness: A randomised controlled trial examining the 36 month costs, benefits and social outcomes from the Journey to Social Inclusion Pilot Pogram. St. Kilda, Sacred Heart Mission.

Kling, J. 2006. 'Incarceration length, employment and earning.' American Economic Review 96 (3): 863-876.

Kuhn, R. and D. Culhane. 1998. 'Patterns and determinants of public shelter utilization among homeless adults in New York City and Philadelphia.' Journal of Policy Analysis and Management 17(1): 23-44. 
Kushei, M., J. Hahn, J. Evans, D. Bangsberg and A. Moss. 2005. 'Revolving doors: imprisonment among the homeless and marginally housed population.' American Journal of Public Health 95(10): 1747-1752.

Massoglia, M., G. Firebaugh and C. Warner. 2012. 'Racial variation in the effect of incarceration on neighborhood attainment.' American Sociological Review 78(1): 142165.

Melbourne Institute. 2014. 'Journeys Home Wave 6 Technical Report - Fieldwork, Response and Weighting.' Report Prepared for the Australian Government Department of Social Services.

Mccarthy, B. and J. Hagan. 1991. 'Homelessness: A criminogenic situation?' British Journal of Crimonology 31(4): 393-410.

Mcvicar, D., J. Moschion and J. Van Ours. 2015. 'From substance use to homelessness or visa versa?' Social Science and Medicine 136-137:89-98.

Metraux, S. and D. Culhane. 2004. 'Homeless shelter use and reincarceration following prison release.' Criminology and Public Policy 3(2): 139-160.

Metraux, S., C. Roman and R. Cho. 2007. Incarceration and Homelessness. National Symposium on Homelessness Research. Washington.

Metraux, S., M. Cusack, T. Bryne, N. Hunt-Johnson and G. True (2017). 'Pathways into homelessness among post 9/11 era veterans' Psychologial Services. 14(2): 229-237

Michaels, D., S. Zoloth, P. Alcabes, C. Braslow and S. Safyer. 1992. 'Homelessness and indicators of mental illness among inmates in New York City's correctional system.' Hospital and Community Psychiatry 43: 150-155.

Naser, R. and N. Lavigne. 2006. 'Family support in the prisoner reentry process.' Journal of Offender Rehabilitation 43(1): 93-106.

Pager, D. 2003. 'The mark of a criminal.' American Journal of Sociology 108(5): 937-975. 
Payne, J., S. Macgregor and H. Mcdonald. 2015. Homelessness and housing stress among police detainees: Results from the DUMA program. Canberra, Australian Institute of Criminology.

Piliavin, I., M. Sosin, A. Westerfelt and R. Matsueda. 1993. 'The duration of homeless careers: An exploratory study.' Social Service Review 67(4): 576-598.

Redburn, F. S. and T. F. Buss. 1986. Responding to America's Homeless: Public Policy Alternatives. New York, Praeger.

Ribton-Turner, C. J. 1972. History of Vagrants and Vagrancy and Beggars and Begging. New Jersey, Patterson Smith.

Rossi, P. 1989. Down and Out in America: The Origins of Homelessness. Chicago, Chicago University Press.

Schwartz-Soicher, O., A. Geller and I. Garfinkel. 2011. 'The effect of paternal incarceration on material hardship.' Social Service Review 85(3): 447-473.

Shlay, A. and P. Rossi. 1992. 'Social science research and contemporary studies of homelessness.' Annual Review of Sociology 18: 129-160.

Snow, D. and L. Anderson. 1993. Down on their luck: A study of street homeless people. Berkeley, University of California Press.

Snow, D., S. Baker and L. Anderson. 1989. 'Criminality and homeless men: An empirical assessment.' Social Problems 36(5): 532-549.

Sutherland, E. and H. Locke 1936. Twenty Thousand Homeless Men: A Study of Unemployed Men in the Chicago Shelters. Philadelphia, JB Lippincott.

Visher, C., N. La Vigne and J. Travis. 2004. Returning home: Understanding the challenges of prisoner reentry: Maryland Pilot Study. Washington, DC, The Urban Institute.

Visher, C. and J. Travis. 2003. 'Transtion from prison to community: Understanding individual pathways.' American Review of Sociology 29: 89-113. 
Walker, A., L. Hempel, N. Unnithan and M. Pogrebin. 2014. 'Parole re-entry and social capital: The centrality of homelessness.' Journal of Poverty 18(3): 315-334.

Walsh, T. 2011. Homelessness and the Law. Sydney, The Federation Press.

Western, B., A. Braga, J. Davis and C. Sirois. 2015. 'Stress and hardship after prison.' American Journal of Sociology 120(5): 1512-154.

Williams, K., J. Poyser and K. Hopkins. 2012. Accommodation, homelessness and reoffending of prisoners: results from the Surveying Prisoner Crime Reduction (SPCR) survey. London, Ministry of Justice.

Wolch, J. and M. Dear. 1993. Malign Neglect: Homelessness in an American City. San Francisco, Jossey-Bass Publishers.

Wooden, M., A. Bevitt, A. Chigavazira, N. Greer, G. Johnson, E. Killackey, J. Mocschion, R. Scutella, Y. Tseng and N. Watson. 2012. 'Introducing Journeys Home.' Australian Economic Review 45(3): 326-336. 
Table 1: Descriptive statistics for homelessness and incarceration

\begin{tabular}{|c|c|c|c|c|}
\hline & \multicolumn{3}{|c|}{ WAVE DATA } & \multirow{2}{*}{$\begin{array}{c}\text { SPELL DATA } \\
\text { Balanced panel } \\
\text { over } 6 \text { waves }\end{array}$} \\
\hline & $\begin{array}{c}\text { Wave } 1 \\
\text { respondents }\end{array}$ & $\begin{array}{l}\text { Balanced panel } \\
\text { W1 charact. }\end{array}$ & $\begin{array}{c}\text { Balanced panel } \\
\text { over } 6 \text { waves }\end{array}$ & \\
\hline \multicolumn{5}{|l|}{ Outcomes } \\
\hline Homelessness (any) & 46.6 & $44.7 *$ & 31.2 & 36.4 \\
\hline Literal homelessness & 19.5 & $17.4^{*}$ & 9.4 & 9.0 \\
\hline \multicolumn{5}{|l|}{ Precariously Housed } \\
\hline Staying at a boarding house & 14.0 & 12.8 & 8.1 & 5.6 \\
\hline Staying with friends & 25.5 & 24.7 & 14.5 & 17.1 \\
\hline Staying at a caravan park or hotel & 13.6 & 13.8 & 7.2 & 4.7 \\
\hline Incarcerated & 4.7 & $3.8^{*}$ & 3.9 & - \\
\hline Incarcerated (calendar) & 1.5 & 1.2 & 1.8 & 0.9 \\
\hline Number of observations & 1,682 & 1,211 & 7,266 & 5,291 \\
\hline \multicolumn{5}{|c|}{$\begin{array}{l}\text { * Denote significant differences with the characteristics of wave } 1 \text { respondents reported in column } 1 . \\
\text { NOTE: In the first three columns (wave data), the homelessness and incarceration variables are indicator } \\
\text { variables for whether the respondent has been homeless / incarcerated in a specific wave. The respondent may } \\
\text { have experienced different forms of homelessness over that period such that the sum of the percentage of } \\
\text { respondents experiencing literal homelessness and different types of precarious housing is larger than the } \\
\text { percentage of respondents experiencing any type of homelessness (first row). In the last column, (spell data), the } \\
\text { homelessness and incarceration variables are indicator variables for whether the respondent is homeless / } \\
\text { incarcerated in a specific spell. Here each spell of homelessness can only be of one type such that the sum of the } \\
\text { percentage of respondents experiencing literal homelessness and different types of precarious housing is equal } \\
\text { to the percentage of respondents experiencing any type of homelessness (first row). The first incarceration } \\
\text { variable is an indicator variable using all sources of information available (calendar, administrative, interview } \\
\text { status, respondent), while the last row is an indicator variable only using the information reported in the calendar }\end{array}$} \\
\hline
\end{tabular}


Table 2: Relationship between homelessness and incarceration before JH (\%)

\begin{tabular}{lccc}
\hline & $\begin{array}{c}\text { Never } \\
\text { incarcerated }\end{array}$ & Incarcerated & $\mathrm{N}$ \\
\hline Never homeless & 88.7 & 11.3 & 133 \\
Ever in precarious housing & 84.3 & 15.7 & 249 \\
Ever literally homeless & 58.5 & 41.6 & 828 \\
\hline
\end{tabular}

NOTE: Respondents in second row have been in precarious housing but were never literally homeless; those in the third row have been literally homeless and may also have been in precarious housing. 
Table 3: The effect of incarceration on homelessness

\section{Outcome in $\mathrm{t}+1$ : Homelessness}

$\begin{array}{lll}\text { No control } & \begin{array}{l}\text { First set of } \\ \text { controls }\end{array} & \begin{array}{l}\text { Second set of } \\ \text { controls }^{3}\end{array}\end{array}$

Incarceration variable:

a. Geller \& Curtis (2011), logit OR

In the first $5 \mathrm{Y}(\mathrm{Y} 1-\mathrm{Y} 5)$

$$
2.68^{* *}
$$

b. GC (2011) with our data, logit OR

In the first 5 waves

$1.760 * * *$

$1.753 * * *$

$1.825^{* * *}$

$(0.380)$

(0.449)

(0.468)

$\mathrm{N}$

1,143

1,143

1,143

c. GC (2011) with our data, OLS

In the first 5 waves

$0.118^{* *}$

$0.108 * *$

$0.113^{* *}$

(0.054)

(0.054)

$\mathrm{N}$

1,143

1,143

1,143

\section{$\underline{\text { d. Panel data, }}$ OLS $^{4}$}

In $\mathrm{t}$

$0.120 * * *$

0.059

0.042

$(0.042)$

$(0.042)$

(0.042)

$\mathrm{N}$

5,746

5,746

5,746

e. Panel data, Individual fixed effects ${ }^{4}$

In $\mathrm{t}$

\subsection{3}

0.009

0.050

$(0.042)$

$(0.020)$

${ }^{1}$ The outcome in panels $\mathrm{b}$ and $\mathrm{c}$ is a dummy for whether the respondent was homeless between waves 5 and 6 . In panels $\mathrm{d}$ and $\mathrm{e}$, the outcome is a dummy for whether the respondent was homeless between wave $t$ and wave $(\mathrm{t}+1)$.

${ }^{2}$ First set of controls

*Time-invariant (except in the fixed effects model): a dummy for having ever been incarcerated before Journeys Home, a dummy for having ever been homeless before Journeys Home, a dummy for male, a dummy for being indigenous, a dummy for being born in an English-speaking country, a dummy for not living with biological parents at 14, five dummies for the female and male caregivers (substance abuse, long-term unemployment, mental health, incarceration, gambling), the Big 5 personality traits (extroversion, agreeableness, conscientiousness, emotional stability, openness to experience), cognitive ability (0-7 score), missing data indicators.

*Time-varying: respondent's age and age square, a dummy for being divorced/separated, two dummies for the level of education (high-school graduate, some college), dummy for being employed, four dummies for the use of substances (smoking daily, risky drinking, cannabis, illegal street drugs), a dummy for reporting good health, seven dummies for State, missing data indicators.

${ }^{3}$ Second set of controls:

* Time-varying: a dummy for having resident children under 18, two dummies for having experienced violence in the last 6 months (physical and sexual), the proportion of time employed in the last 6 months, total outstanding debt, a dummy for having contacts with family less than once a month, two dummies for all/most friends being homeless/ using illicit drugs, missing data indicators

${ }^{4}$ Panels $\mathrm{d}$ and e also include wave fixed effects.

Standard errors reported in parenthesis and clustered at the individual level. 
Table 4: The effect of homelessness on incarceration

Outcome in $\mathrm{t}+1$ : Incarceration

$\begin{array}{lll}\text { No control } & \begin{array}{l}\text { First set of } \\ \text { controls }\end{array} & \begin{array}{l}\text { Second set of } \\ \text { controls }\end{array}\end{array}$

Homelessness:

a. Panel data, OLS

$\begin{array}{llll}\text { In } \mathrm{t} & 0.014^{* *} & 0.006 & 0.005 \\ & (0.006) & (0.006) & (0.006) \\ \mathrm{N} & 5,805 & 5,805 & 5,805\end{array}$

b. Panel data, Individual fixed effects

\begin{tabular}{clll} 
In $\mathrm{t}$ & 0.000 & 0.000 & 0.000 \\
& $(0.008)$ & $(0.008)$ & $(0.008)$ \\
$\mathrm{N}$ & 5,805 & 5,805 & 5,805 \\
\hline
\end{tabular}

Controls: as models $\mathrm{d}$ and $\mathrm{e}$ in Table 3 .

Standard errors reported in parenthesis and clustered at the individual level.

The outcome is a dummy for whether the respondent was incarcerated between wave $t$ and wave $(t+1)$. 
Table 5: The effect of contacts with the justice system on different components of homelessness

\begin{tabular}{|c|c|c|c|c|c|}
\hline & $\begin{array}{l}\text { Homelessness } \\
\text { (1) }\end{array}$ & $\begin{array}{l}\text { Literally } \\
\text { Homeless } \\
(2)\end{array}$ & $\begin{array}{l}\text { Boarding } \\
\text { house } \\
\text { (3) }\end{array}$ & $\begin{array}{l}\text { Friend's } \\
\text { house } \\
\text { (4) }\end{array}$ & $\begin{array}{l}\text { Caravan park } \\
\text { or hotel } \\
\text { (5) }\end{array}$ \\
\hline \multicolumn{6}{|c|}{ Incarceration } \\
\hline In $\mathrm{t}$ & $\begin{array}{l}0.050 \\
(0.043)\end{array}$ & $\begin{array}{l}-0.014 \\
(0.039)\end{array}$ & $\begin{array}{l}0.017 \\
(0.031)\end{array}$ & $\begin{array}{l}0.073 \\
(0.048)\end{array}$ & $\begin{array}{l}0.032 \\
(0.023)\end{array}$ \\
\hline $\mathrm{N}$ & 5,746 & 4,577 & 4,542 & 4,830 & 4,461 \\
\hline \multicolumn{6}{|c|}{ Stopped by police in the street } \\
\hline In $t$ & $\begin{array}{l}0.053 * * * \\
(0.016)\end{array}$ & $\begin{array}{l}0.028^{* *} \\
(0.013)\end{array}$ & $\begin{array}{l}0.002 \\
(0.010)\end{array}$ & $\begin{array}{l}0.043 * * * \\
(0.016)\end{array}$ & $\begin{array}{l}0.021 * * \\
(0.010)\end{array}$ \\
\hline $\mathrm{N}$ & 5,722 & 4,559 & 4,523 & 4,811 & 4,443 \\
\hline \multicolumn{6}{|c|}{ Held overnight by the police } \\
\hline In $t$ & $\begin{array}{l}0.053 * \\
(0.027)\end{array}$ & $\begin{array}{l}0.013 \\
(0.022)\end{array}$ & $\begin{array}{l}0.009 \\
(0.018)\end{array}$ & $\begin{array}{l}0.053 * \\
(0.030)\end{array}$ & $\begin{array}{l}0.013 \\
(0.018)\end{array}$ \\
\hline $\mathrm{N}$ & 5,723 & 4,560 & 4,525 & 4,813 & 4,445 \\
\hline \multicolumn{6}{|l|}{ Court } \\
\hline In $\mathrm{t}$ & $\begin{array}{l}0.030^{*} \\
(0.018)\end{array}$ & $\begin{array}{l}0.009 \\
(0.013)\end{array}$ & $\begin{array}{l}0.007 \\
(0.010)\end{array}$ & $\begin{array}{l}0.032 * \\
(0.017)\end{array}$ & $\begin{array}{l}-0.003 \\
(0.013)\end{array}$ \\
\hline $\mathrm{N}$ & 5,720 & 4,557 & 4,522 & 4,810 & 4,442 \\
\hline \multicolumn{6}{|c|}{ Apprehended by the police } \\
\hline In $\mathrm{t}$ & $\begin{array}{l}0.036 \\
(0.023)\end{array}$ & $\begin{array}{l}0.029 \\
(0.020)\end{array}$ & $\begin{array}{l}0.006 \\
(0.016)\end{array}$ & $\begin{array}{l}0.040^{*} \\
(0.024)\end{array}$ & $\begin{array}{l}0.008 \\
(0.015)\end{array}$ \\
\hline $\mathrm{N}$ & 5,721 & 4,558 & 4,523 & 4,811 & 4,443 \\
\hline \multicolumn{6}{|c|}{ Non-custodial sentence or community based order } \\
\hline In $\mathrm{t}$ & $\begin{array}{l}0.047 \\
(0.029)\end{array}$ & $\begin{array}{l}-0.004 \\
(0.021)\end{array}$ & $\begin{array}{l}0.000 \\
(0.018)\end{array}$ & $\begin{array}{l}0.034 \\
(0.032)\end{array}$ & $\begin{array}{l}0.008 \\
(0.017)\end{array}$ \\
\hline $\mathrm{N}$ & 5,711 & 4,550 & 4,515 & 4,802 & 4,436 \\
\hline \multicolumn{6}{|c|}{ Visits to/from Justice Officers } \\
\hline In $\mathrm{t}$ & $\begin{array}{l}-0.012 \\
(0.025)\end{array}$ & $\begin{array}{l}0.013 \\
(0.023)\end{array}$ & $\begin{array}{l}0.020 \\
(0.014)\end{array}$ & $\begin{array}{l}-0.029 \\
(0.026)\end{array}$ & $\begin{array}{l}0.000 \\
(0.016)\end{array}$ \\
\hline $\mathrm{N}$ & 5,722 & 4,559 & 4,525 & 4,813 & 4,445 \\
\hline \multicolumn{6}{|c|}{ Stopped in a vehicle by police } \\
\hline In $\mathrm{t}$ & $\begin{array}{l}0.001 \\
(0.014)\end{array}$ & $\begin{array}{l}0.004 \\
(0.011)\end{array}$ & $\begin{array}{l}0.001 \\
(0.008)\end{array}$ & $\begin{array}{l}0.011 \\
(0.014)\end{array}$ & $\begin{array}{l}-0.007 \\
(0.008)\end{array}$ \\
\hline $\mathrm{N}$ & 5,721 & 4,560 & 4,523 & 4,811 & 4,444 \\
\hline
\end{tabular}

Controls: as model e in Table 3.

Standard errors reported in parenthesis and clustered at the individual level. 
Table 6: The effect of different components of homelessness on incarceration and contact with the justice system

\begin{tabular}{|c|c|c|c|c|c|c|c|c|}
\hline & Incarcer. & $\begin{array}{l}\text { Stopped } \\
\text { by police } \\
\text { in the } \\
\text { street }\end{array}$ & $\begin{array}{l}\text { Held } \\
\text { overnig. } \\
\text { by the } \\
\text { police }\end{array}$ & Court & $\begin{array}{l}\text { Non- } \\
\text { custodial } \\
\text { sentence or } \\
\text { commu. } \\
\text { based } \\
\text { order }\end{array}$ & $\begin{array}{l}\text { Appreh. } \\
\text { by the } \\
\text { police }\end{array}$ & $\begin{array}{l}\text { Visits } \\
\text { to/from } \\
\text { Justice } \\
\text { Officers }\end{array}$ & $\begin{array}{l}\text { Stopped } \\
\text { in a } \\
\text { vehicle } \\
\text { by police }\end{array}$ \\
\hline \multicolumn{9}{|c|}{ Homelessness } \\
\hline In $\mathrm{t}$ & $\begin{array}{l}0.000 \\
(0.008)\end{array}$ & $\begin{array}{l}-0.005 \\
(0.015)\end{array}$ & $\begin{array}{l}0.003 \\
(0.009)\end{array}$ & $\begin{array}{l}0.002 \\
(0.014)\end{array}$ & $\begin{array}{l}-0.001 \\
(0.008)\end{array}$ & $\begin{array}{l}0.014 \\
(0.011)\end{array}$ & $\begin{array}{l}0.002 \\
(0.009)\end{array}$ & $\begin{array}{l}-0.008 \\
(0.016)\end{array}$ \\
\hline $\mathrm{N}$ & 5,805 & 5,762 & 5,763 & 5,759 & 5,754 & 5,760 & 5,761 & 5,762 \\
\hline \multicolumn{9}{|c|}{ Literally homeless } \\
\hline In $\mathrm{t}$ & $\begin{array}{l}0.008 \\
(0.012)\end{array}$ & $\begin{array}{l}-0.023 \\
(0.021)\end{array}$ & $\begin{array}{l}-0.006 \\
(0.014)\end{array}$ & $\begin{array}{l}0.026 \\
(0.022)\end{array}$ & $\begin{array}{l}0.011 \\
(0.013)\end{array}$ & $\begin{array}{l}0.010 \\
(0.020)\end{array}$ & $\begin{array}{l}0.018 \\
(0.013)\end{array}$ & $\begin{array}{l}0.035 \\
(0.023)\end{array}$ \\
\hline \multicolumn{9}{|c|}{ Boarding house } \\
\hline In $\mathrm{t}$ & $\begin{array}{l}-0.009 \\
(0.015)\end{array}$ & $\begin{array}{l}0.039 \\
(0.030)\end{array}$ & $\begin{array}{l}-0.003 \\
(0.020)\end{array}$ & $\begin{array}{l}0.023 \\
(0.028)\end{array}$ & $\begin{array}{l}0.018 \\
(0.017)\end{array}$ & $\begin{array}{l}0.067 * * \\
(0.029)\end{array}$ & $\begin{array}{l}0.013 \\
(0.019)\end{array}$ & $\begin{array}{l}-0.013 \\
(0.029)\end{array}$ \\
\hline \multicolumn{9}{|c|}{ Friend's house } \\
\hline In $\mathrm{t}$ & $\begin{array}{l}-0.004 \\
(0.009)\end{array}$ & $\begin{array}{l}0.001 \\
(0.018)\end{array}$ & $\begin{array}{l}0.001 \\
(0.011)\end{array}$ & $\begin{array}{l}0.014 \\
(0.017)\end{array}$ & $\begin{array}{l}-0.014 \\
(0.010)\end{array}$ & $\begin{array}{l}-0.004 \\
(0.014)\end{array}$ & $\begin{array}{l}-0.020 * \\
(0.011)\end{array}$ & $\begin{array}{l}-0.014 \\
(0.020)\end{array}$ \\
\hline \multicolumn{9}{|c|}{$\frac{\text { Caravan park or }}{\text { hotel }}$} \\
\hline In $\mathrm{t}$ & $\begin{array}{l}-0.002 \\
(0.009)\end{array}$ & $\begin{array}{l}0.009 \\
(0.025)\end{array}$ & $\begin{array}{l}0.004 \\
(0.016)\end{array}$ & $\begin{array}{l}0.005 \\
(0.027)\end{array}$ & $\begin{array}{l}0.022 \\
(0.016)\end{array}$ & $\begin{array}{l}-0.017 \\
(0.019)\end{array}$ & $\begin{array}{l}0.036 * * \\
(0.018)\end{array}$ & $\begin{array}{l}-0.032 \\
(0.028)\end{array}$ \\
\hline $\mathrm{N}$ & 5,776 & 5,733 & 5,734 & 5,730 & 5,725 & 5,731 & 5,732 & 5,733 \\
\hline
\end{tabular}

Controls: as model e in Table 3.

Standard errors reported in parenthesis and clustered at the individual level. 
Table 7: Robustness checks

Outcome in $\mathrm{t}+1$ :

\begin{tabular}{|c|c|c|c|c|}
\hline \multirow{3}{*}{$\begin{array}{l}\text { Incarceration / } \\
\text { Homelessness }\end{array}$} & \multicolumn{4}{|c|}{ Outcome in $\mathrm{t}+1$ : } \\
\hline & \multicolumn{2}{|c|}{ Homelessness } & \multicolumn{2}{|c|}{ Incarceration } \\
\hline & Coefficient & s.e. & Coefficient & s.e. \\
\hline $\begin{array}{l}\text { Uncorrected calendar } \\
\text { variable }\end{array}$ & $0.094 *$ & $(0.055)$ & 0.001 & $(0.006)$ \\
\hline $\mathbf{N}$ & \multicolumn{2}{|c|}{5,729} & \multicolumn{2}{|c|}{5,766} \\
\hline Controls in wave $\mathrm{t}+1$ & 0.056 & $(0.041)$ & 0.003 & $(0.007)$ \\
\hline $\mathbf{N}$ & \multicolumn{2}{|c|}{5,746} & \multicolumn{2}{|c|}{5,805} \\
\hline \multirow[t]{2}{*}{$\begin{array}{l}\text { Control for incarceration / } \\
\text { homelessness in wave } t+1\end{array}$} & 0.050 & $(0.043)$ & 0.003 & $(0.007)$ \\
\hline & \multicolumn{2}{|c|}{5,746} & \multicolumn{2}{|c|}{5,590} \\
\hline $\begin{array}{l}\text { Clustering s.e. at the cluster } \\
\text { level }\end{array}$ & 0.050 & $(0.042)$ & 0.000 & $(0.008)$ \\
\hline $\mathbf{N}$ & \multicolumn{2}{|c|}{5,746} & \multicolumn{2}{|c|}{5,805} \\
\hline Unbalanced panel & 0.053 & $(0.038)$ & 0.002 & $(0.007)$ \\
\hline $\mathbf{N}$ & \multicolumn{2}{|c|}{6,722} & \multicolumn{2}{|c|}{6,806} \\
\hline
\end{tabular}

Controls: as model e in Table 3 (unless specified).

Standard errors reported in parenthesis and clustered at the individual level (unless specified). 
Figure 1: The spells data - the effect of incarceration on homelessness

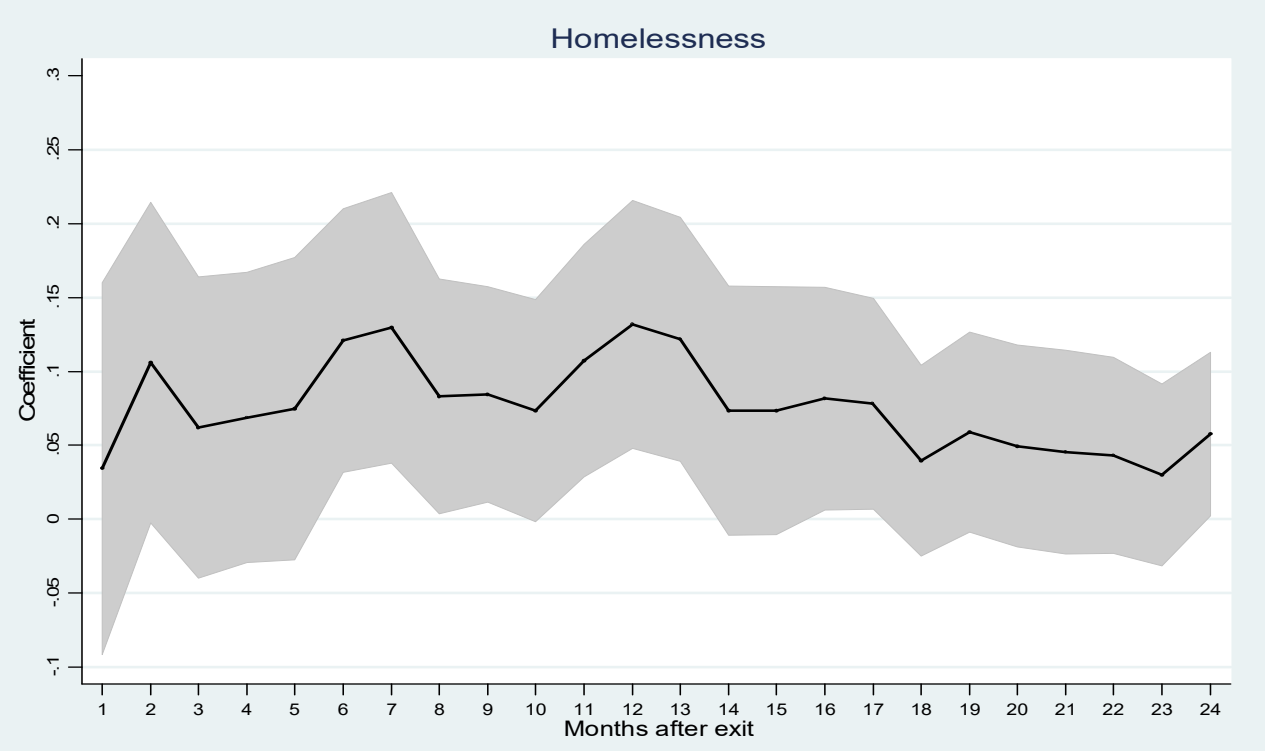

Controls (at the wave level, taken in the wave prior to the main incarceration / homelessness explanatory variable): as in model e in Table 3.

$95 \%$ confidence intervals represented in grey (standard errors clustered at the individual level). 
Figure 2: The spells data - the effect of incarceration on homelessness, by accommodation type
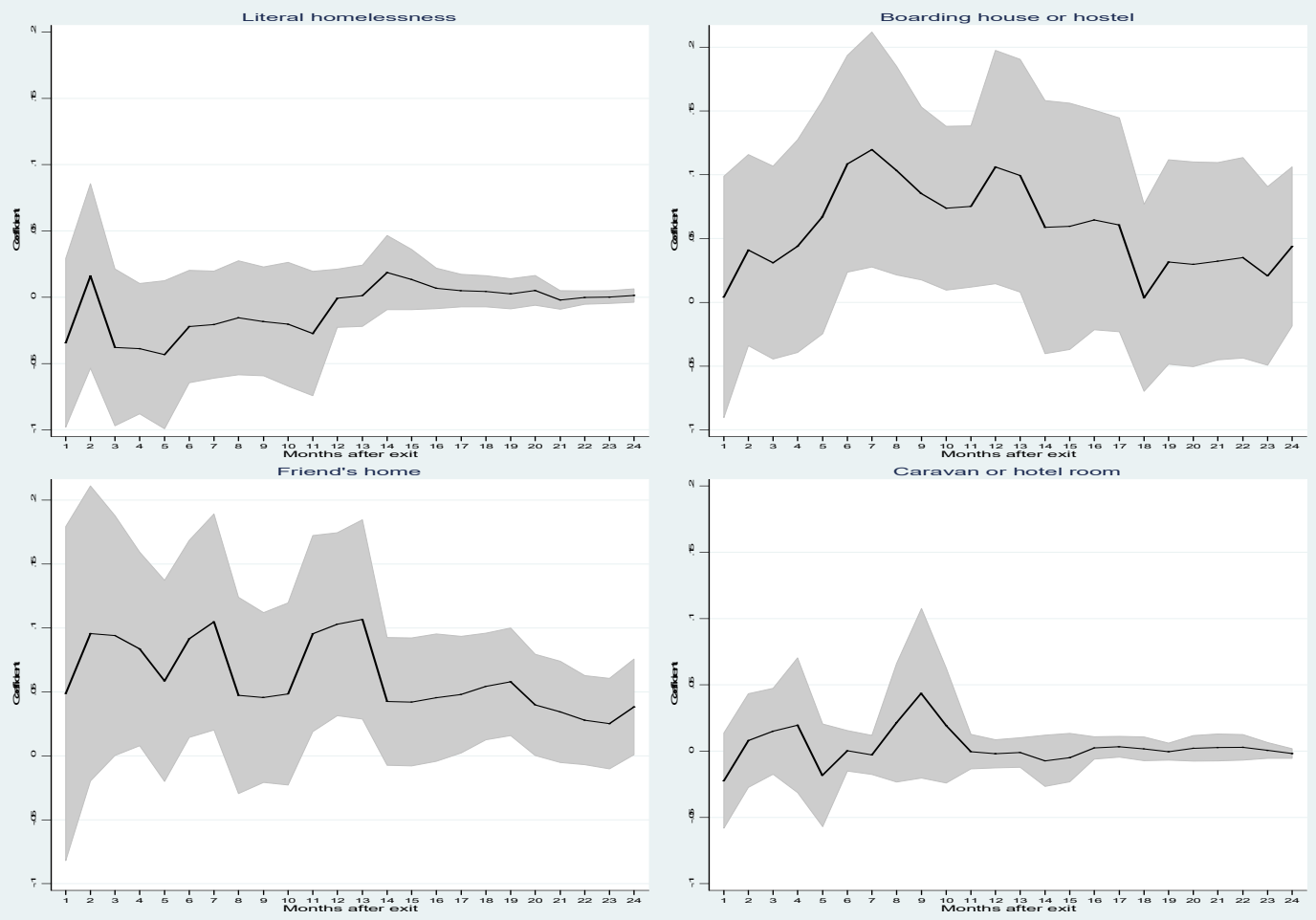

Controls (at the wave level, taken in the wave prior to the main incarceration / homelessness explanatory variable): as in model e in Table 3.

$95 \%$ confidence intervals represented in grey (standard errors clustered at the individual level). 
Figure 3: The spells data - the effect of homelessness on incarceration

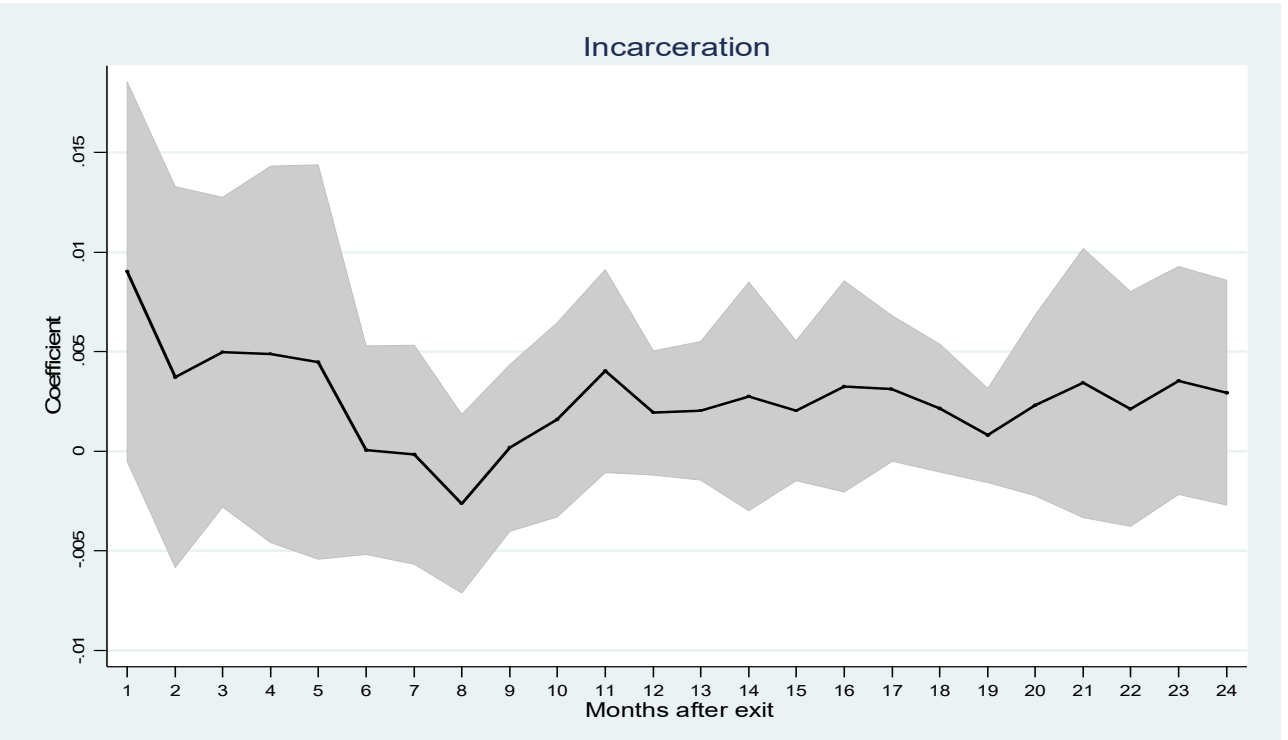

Controls (at the wave level, taken in the wave prior to the main incarceration / homelessness explanatory variable): as in model e in Table 3.

$95 \%$ confidence intervals represented in grey (standard errors clustered at the individual level). 


\section{Appendix}

Table A1

\begin{tabular}{|c|c|c|c|c|}
\hline & $\begin{array}{l}\text { Wave } 1 \\
\text { respondents }\end{array}$ & $\begin{array}{c}\text { NAVE DATA } \\
\text { Balanced } \\
\text { panel } \\
\text { W1 charact. }\end{array}$ & $\begin{array}{c}\text { Balanced } \\
\text { panel } 6 \\
\text { waves } \\
\end{array}$ & $\begin{array}{c}\text { SPELL } \\
\text { DATA } \\
\text { Balanced } \\
\text { panel } 6 \\
\text { waves } \\
\end{array}$ \\
\hline \multicolumn{5}{|l|}{$\underline{\text { Time-varying variables }}$} \\
\hline Age & 31.9 & 32.1 & 33.4 & 30.7 \\
\hline Divorced / separated & 20.1 & 21.1 & 20.1 & 17.4 \\
\hline Completed Year 12 & 27.8 & 28.5 & 33.3 & 30.9 \\
\hline Holds a tertiary qualification & 11.5 & 11.6 & 10.9 & 9.6 \\
\hline Employed in last $6 \mathrm{~m}$ & 20.0 & 20.6 & 23.9 & 20.8 \\
\hline Drinking at risky levels in last $6 \mathrm{~m}$ & 17.1 & $15.7 *$ & 15.0 & 17.1 \\
\hline Smoking daily in last $6 \mathrm{~m}$ & 67.9 & 68.1 & 65.6 & 70.6 \\
\hline Cannabis use in last $6 \mathrm{~m}$ & 36.2 & 36.1 & 33.4 & 41.8 \\
\hline Other illegal drug use in last $6 \mathrm{~m}$ & 13.4 & $12.1 *$ & 10.5 & 15.3 \\
\hline Health is at least good & 62.3 & 60.9 & 62.3 & 61.0 \\
\hline New South Wales & 20.2 & 19.9 & 19.7 & 18.4 \\
\hline Victoria & 21.2 & 22.1 & 22.4 & 20.5 \\
\hline Queensland & 26.5 & 27.3 & 26.9 & 27.9 \\
\hline South Australia & 6.5 & 7.1 & 7.4 & 7.2 \\
\hline Western Australia & 10.9 & 10.2 & 10.1 & 11.4 \\
\hline Tasmania & 4.8 & 5.2 & 5.3 & 8.5 \\
\hline Northern Territory & 6.9 & $5.5^{*}$ & 5.3 & 4.7 \\
\hline Australian Capital Territory & 3.0 & 2.9 & 2.9 & 1.4 \\
\hline Lives with dependent children & 19.8 & $22.0 *$ & 25.7 & 20.3 \\
\hline Experienced physical violence in last $6 \mathrm{~m}$ & 17.7 & 18.5 & 16.6 & 22.8 \\
\hline Experienced sexual violence in last $6 \mathrm{~m}$ & 2.1 & 2.3 & 1.9 & 2.4 \\
\hline Proportion of time employed in last $6 \mathrm{~m}$ & 0.9 & 0.9 & 0.5 & 0.7 \\
\hline Total outstanding debt (in AUD) & 5113.3 & 5233.6 & 4901.2 & 5105.8 \\
\hline Contacts with family less than once a month & 20.1 & 19.0 & 18.1 & 18.9 \\
\hline All/most friends are homeless & 9.3 & 9.9 & 6.3 & 8.9 \\
\hline All/most friends are using illegal drugs & 18.2 & 18.4 & 15.7 & 20.4 \\
\hline Missing information on violence & 12.4 & $10.3^{*}$ & 5.6 & 6.2 \\
\hline Missing information on employment & 2.1 & 1.9 & 34.6 & 13.5 \\
\hline Missing information on debt & 8.7 & 7.9 & 7.4 & 7.9 \\
\hline Missing information on friends' homelessness & 16.3 & 15.7 & 15.1 & 15.2 \\
\hline Missing information on friends' drug use & 16.4 & 15.8 & 15.3 & 15.4 \\
\hline \multicolumn{5}{|l|}{$\underline{\text { Time-invariant variables }}$} \\
\hline Was ever homeless before Journeys Home & 88.9 & 89.0 & 89.0 & 91.3 \\
\hline Was ever incarcerated before Journeys Home & 34.5 & 33.0 & 33.0 & 35.2 \\
\hline Male & 54.5 & 53.4 & 53.4 & 54.9 \\
\hline Indigenous (including Torres Straight Islander) & 19.7 & $17.7 *$ & 17.7 & 19.0 \\
\hline Born in an English speaking country & 93.3 & 94.0 & 94.0 & 95.7 \\
\hline
\end{tabular}


Was living with biological parent(s) at 14

Male caregiver

Had an alcohol or drug problem

Spent time in jail

81.9

$83.2 *$

83.2

81.9

Spent time in hospital because mental health pbs

Was unemployed more than $6 \mathrm{~m}$

Had a gambling problem

Female caregiver

Had an alcohol or drug problem

Spent time in jail

29.5

29.7

29.7

30.9

10.4

10.7

10.7

12.0

Spent time in hospital because mental health pbs

Was unemployed more than $6 \mathrm{~m}$

5.1

16.8

4.9

8.6

$15.0 *$

4.9

5.6

8.3

15.0

16.4

17.4

17.1

8.3

7.9

2.0

2.0

17.1

18.2

Had a gambling problem

10.9

37.9

7.2

10.8

2.0

2.7

10.8

10.8

11.7

38.6

38.6

39.3

Big 5 Personnality traits

Extroversion

Agreeableness

Conscientiousness

Emotional stability

Openness

Cognitive ability score

Missing information on male caregiver

Missing information on female caregiver

Number of observations

\begin{tabular}{lcc|c}
2.9 & $3.4^{*}$ & 3.4 & 3.4 \\
3.3 & $3.9^{*}$ & 3.9 & 3.9 \\
3.0 & $3.5^{*}$ & 3.5 & 3.5 \\
2.5 & $3.0^{*}$ & 3.0 & 2.9 \\
3.0 & $3.5^{*}$ & 3.5 & 3.5 \\
2.7 & $3.3^{*}$ & 3.3 & 3.3 \\
11.3 & 11.0 & 11.0 & 11.4 \\
12.8 & $11.7^{*}$ & 11.7 & 11.6 \\
1,682 & 1,211 & 7,266 & 5,291 \\
\hline
\end{tabular}

* Denote significant differences with the characteristics of wave 1 respondents reported in column 1. 
Table A2: Complete estimates reported in Table 3 panel e and Table 4 panel b with the second set of controls

\begin{tabular}{|c|c|c|c|c|}
\hline & \multicolumn{4}{|c|}{ Outcome in $\mathrm{t}+1$ : } \\
\hline & \multicolumn{2}{|c|}{ Housing difficulties } & \multicolumn{2}{|c|}{ Incarceration } \\
\hline & Coefficient & s.e. & Coefficient & s.e. \\
\hline Incarceration / Housing & 0.050 & (0.043) & 0.000 & $(0.008)$ \\
\hline Age & $0.055 * *$ & $(0.024)$ & 0.000 & $(0.010)$ \\
\hline Age square & $-0.001 * *$ & $(0.000)$ & 0.000 & $(0.000)$ \\
\hline Divorced or separated & 0.051 & $(0.050)$ & 0.036 & $(0.028)$ \\
\hline High-school graduate & -0.038 & $(0.041)$ & $-0.031 * *$ & $(0.015)$ \\
\hline Some college & 0.000 & $(0.060)$ & -0.013 & $(0.012)$ \\
\hline Employed & -0.029 & $(0.019)$ & -0.010 & $(0.008)$ \\
\hline Risky drinking & $0.040 * *$ & $(0.020)$ & $0.026 * *$ & $(0.012)$ \\
\hline Smoking daily & 0.000 & $(0.021)$ & -0.007 & $(0.010)$ \\
\hline Cannabis & -0.004 & $(0.020)$ & -0.003 & $(0.010)$ \\
\hline Illegal street drugs & -0.007 & $(0.025)$ & $0.027 * *$ & $(0.013)$ \\
\hline Good health & $-0.046^{* * *}$ & $(0.015)$ & 0.003 & $(0.006)$ \\
\hline Victoria & 0.057 & $(0.081)$ & 0.006 & $(0.023)$ \\
\hline Queensland & 0.053 & $(0.072)$ & 0.025 & $(0.019)$ \\
\hline South Australia & 0.009 & $(0.129)$ & -0.016 & $(0.033)$ \\
\hline Western Australia & $0.207 *$ & $(0.121)$ & 0.054 & $(0.052)$ \\
\hline Tasmania & 0.188 & $(0.199)$ & 0.081 & $(0.065)$ \\
\hline Northern Territory & -0.076 & $(0.153)$ & 0.018 & $(0.023)$ \\
\hline Australian Capital Territory & -0.101 & $(0.141)$ & -0.002 & $(0.019)$ \\
\hline Resident children under 18 & $-0.052 *$ & $(0.027)$ & -0.004 & $(0.012)$ \\
\hline Physical violence in the last 6 months & 0.022 & $(0.018)$ & 0.015 & $(0.010)$ \\
\hline Sexual violence in the last 6 months & 0.037 & $(0.047)$ & -0.025 & $(0.016)$ \\
\hline Proportion of time employed in the last 6 months & 0.009 & $(0.020)$ & $-0.024 * * *$ & $(0.009)$ \\
\hline Total outstanding debt & 0.000 & $(0.000)$ & 0.000 & $(0.000)$ \\
\hline Contacts with family less than once a month & 0.022 & $(0.017)$ & 0.004 & $(0.010)$ \\
\hline All/most friends homeless & -0.008 & $(0.023)$ & $-0.020 *$ & $(0.011)$ \\
\hline All/most friends using illicit drugs & -0.003 & $(0.019)$ & 0.000 & $(0.010)$ \\
\hline Missing data on violence & -0.023 & $(0.025)$ & 0.019 & $(0.013)$ \\
\hline Missing data on employment & -0.027 & $(0.060)$ & -0.018 & $(0.018)$ \\
\hline Missing data on debt & 0.031 & $(0.023)$ & -0.012 & $(0.012)$ \\
\hline Missing data on friends' homelessness & -0.133 & $(0.177)$ & 0.021 & $(0.280)$ \\
\hline Missing data on friends' drug use & 0.100 & $(0.177)$ & -0.005 & $(0.281)$ \\
\hline Wave 2 & $-0.028 *$ & $(0.016)$ & 0.008 & $(0.007)$ \\
\hline Wave 3 & $-0.061 * * *$ & $(0.023)$ & $0.015^{*}$ & $(0.009)$ \\
\hline Wave 4 & $-0.080 * * *$ & $(0.028)$ & 0.019 & $(0.012)$ \\
\hline Wave 5 & -0.053 & $(0.066)$ & 0.031 & $(0.022)$ \\
\hline $\mathrm{N}$ & & & 5,8 & \\
\hline
\end{tabular}


Figure A1: The spells data - the effect of incarceration on other accommodation types
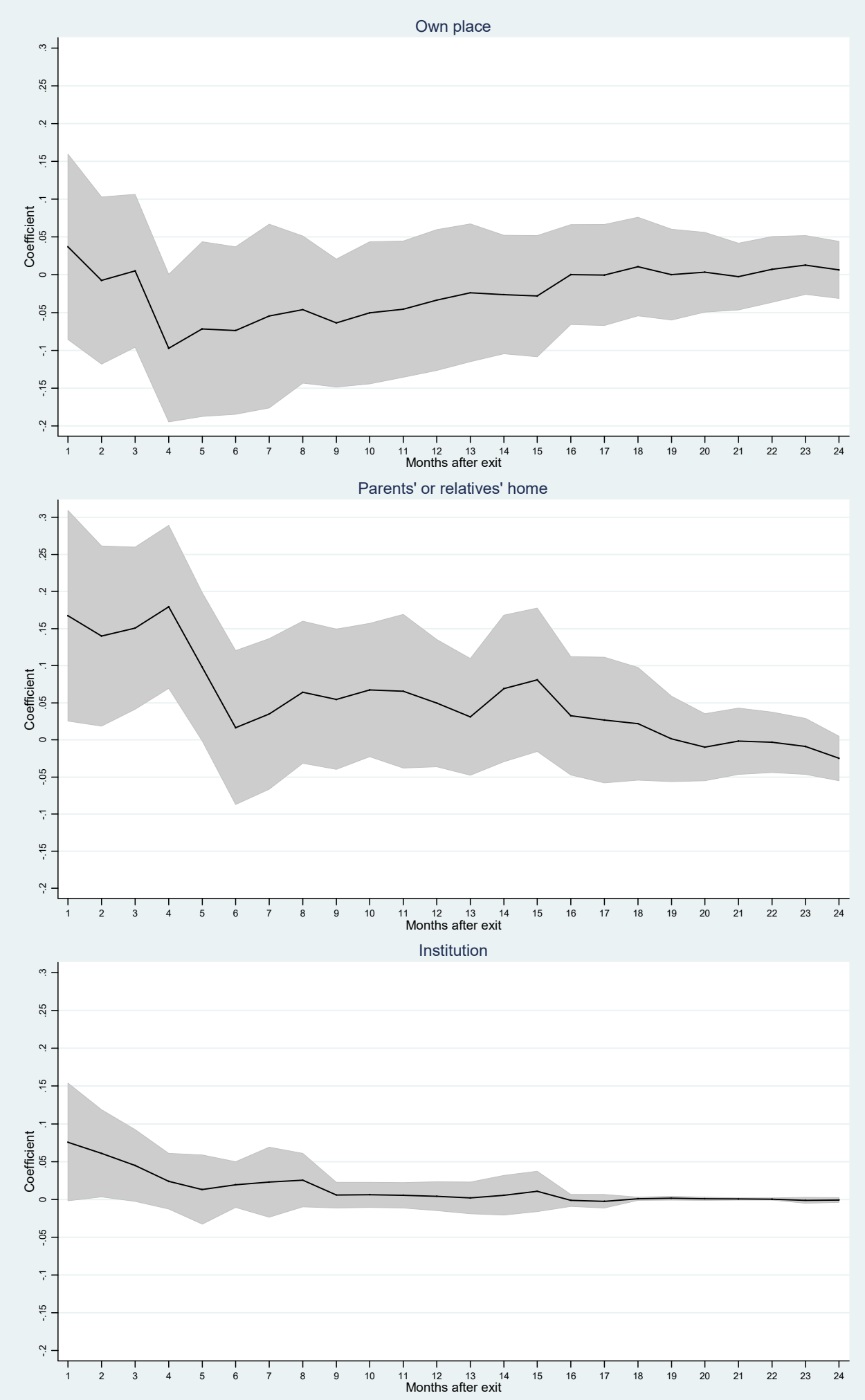
Figure A2: The spells data - the effect of incarceration on homelessness by duration of spell
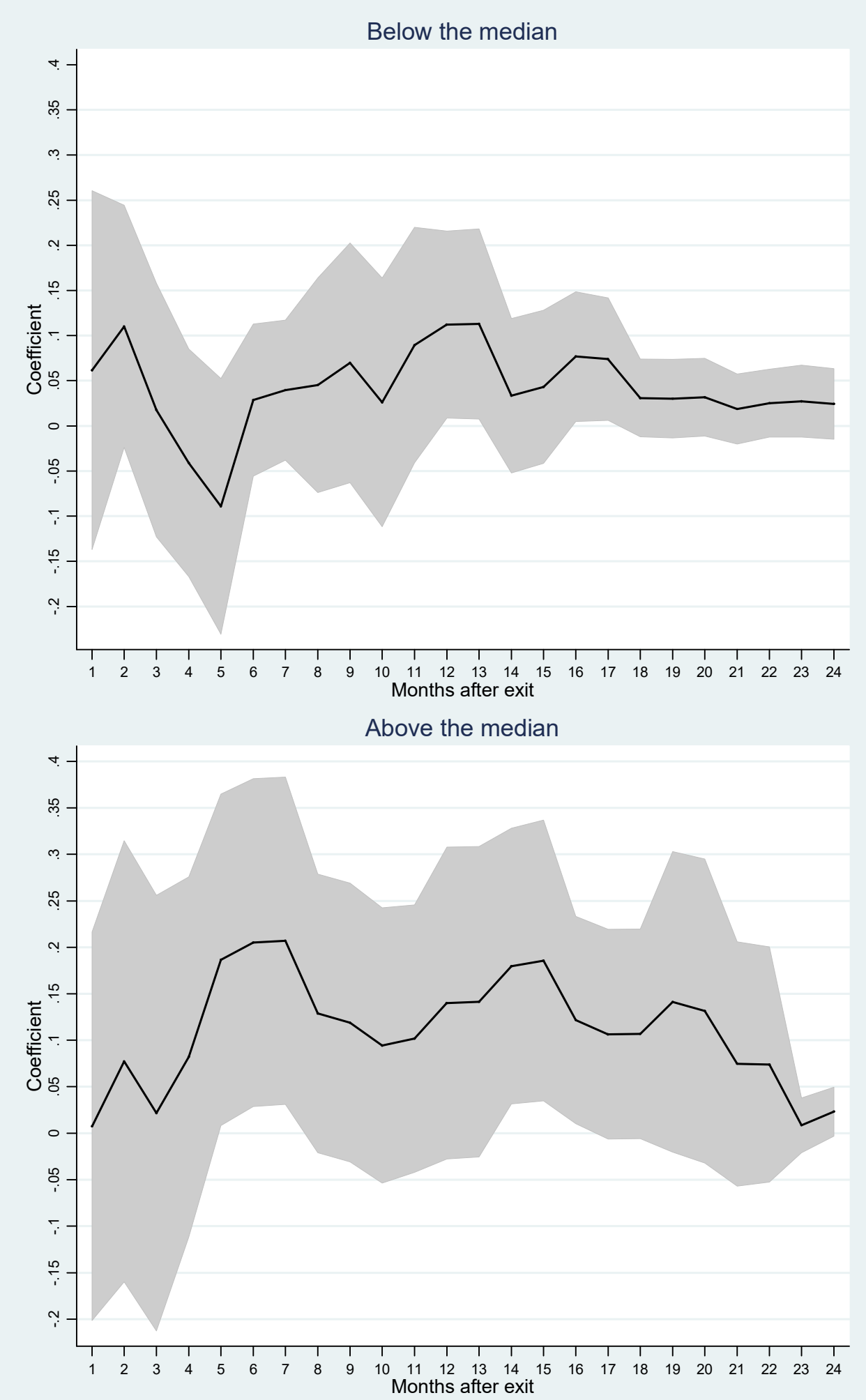